\title{
NARRATIVAS PALEOLÍTICAS: ASPECTOS POCO COMUNES DE LA PUESTA EN ESCENA
}

\section{PALAEOLITHIC NARRATIVES: UNUSUAL ASPECTS OF STAGING}

\author{
Alberto Lombo Montañés* \\ Universidad de Zaragoza
}

\begin{abstract}
RESUMEN. Este trabajo discute el papel de la narración en la cultura humana y en el arte paleolítico. Se recogen algunos casos de grafías animales representadas de espaldas, de frente, desde arriba (serpientes) o emitiendo sonidos, como ejemplos de una inusual puesta en escena. Finalmente, se valora la perspectiva visual en la creación de las grafías paleolíticas y la expresión naturalista de los animales desde diferentes ángulos de visión.

PALABRAS CLAVE. Arte paleolítico, realismo, percepción visual, imaginación.

ABSTRACT. This work discusses the role of storytelling in human culture and Palaeolithic art. Some cases of animal spellings depicted from the back, front, from above (snakes) or making sounds are collected, as examples of unusual staging. Finally, the visual perspective in the creation of Palaeolithic spellings and the naturalistic expression of animals from different viewing angles is valued.
\end{abstract}

KEYWORDS. Palaeolithic art, realism, visual perception, imagination.

* Correspondencia a / Correspondence to: Alberto Lombo Montañés, Universidad de Zaragoza - albertolommon@hotmail.com - https://orcid. org/0000-0003-0972-2459.

Cómo citar / How to cite: Lombo Montañés, Alberto (2021), "Narrativas paleolíticas: aspectos poco comunes de la puesta en escena», Veleia, 38, 33-55. (https://doi.org/10.1387/veleia.22355).

Recibido: 19 diciembre 2020; aceptado: 19 enero 2021.

ISSN 0213-2095 - eISSN 2444-3565 / (C) 2021 UPV/EHU

cc)(i) (-) Esta obra está bajo una licencia

Creative Commons Atribución-NoComercial-SinDerivadas 4.0 Internacional 


\section{INTRODUCCIÓN}

Hace mucho tiempo, en el continente africano, nuestros parientes homínidos pusieron en marcha un nuevo sistema comunicativo (Tomasello 2013). Usaron los recursos expresivos que la naturaleza les había concedido, para extraer y compartir información del medio natural, pero lo hicieron de una manera especial. Pues cuando se tuvieron que adaptar al nuevo entorno terrestre, sus modelos perceptivos tuvieron que remodelarse con relativa rapidez (Gibson 1974, 91). La mayoría de las especies animales tienen enormes dificultades para adecuar sus percepciones originales a nuevos entornos (Gregory 1965, 211); sin embargo, los seres humanos pueden percibir las características de lugares muy diversos. Poseemos un sistema perceptivo muy flexible, capaz incluso de adaptarse a la oscuridad o de calcular distancias en la lejanía (Arnheim 1979, 339; Kanizsa 1998, 61). No es que veamos mejor que una lechuza o un halcón, pero sí que podemos hacerlo de manera más diversa. Esto es así porque desde un principio usamos las percepciones para algo más que desenvolvernos en nuestro entorno circundante. Nuestros parientes homínidos parecían muy interesados en extraer todo tipo de informaciones acerca de la realidad exterior. $\mathrm{Y}$ es aquí donde interviene el lenguaje y sus cualidades narrativas (Victorri 2002; Tomasello 2013, 227). Así se explican las cotas increíblemente sorprendentes que ha alcanzado en nuestra especie el hábito narrativo. Hemos puesto nombres a prácticamente todos los seres vivos de la tierra y contado historias acerca de casi todo lo que se pudiera ver, sentir o percibir. De este modo, narrando la historia de nuestro planeta, nos hemos convertido en sus portavoces. Pero no nos engañemos, esto es tan solo una ilusión más, pues para hacerlo, para conquistar la realidad, el ser humano ha tenido que usar el poder de la imaginación (Bickerton 1994, 209). Dicho de otro modo, la realidad que experimentamos los seres humanos es un mundo imaginado hecho realidad (Bednarik 2016, 167), un universo habitado por nuestras propias representaciones (Cyrulnik 2001, 479). Esto concierne a las escenas naturalistas del arte paleolítico, porque en ellas se puede observar la construcción de un imaginario (Barandiarán 2003). Una de las cuestiones más interesantes de ese ideario es su puesta en escena, pues nos permite observar las relaciones entre los recursos narrativos y el sistema perceptivo con el que el ser humano moldea la realidad cotidiana.

\section{Estado de LA CUESTIÓN Y MÉTOdo}

El término "puesta en escena" proviene del teatro y ha sido aplicado al cine, que lo define como la forma y la composición de los elementos que aparecen en el encuadre (Carmona 2005, 127). En nuestro caso, entendemos por puesta en escena todo lo que concierne a los intérpretes y al espacio de la acción sugerida (Barandiarán 2003, 194), es decir, básicamente, lo distinto al argumento (tema) de la acción. Si se utilizan cada vez más conceptos de este tipo, es porque nos permiten enfocar con mayor claridad algunas cualidades del arte paleolítico. Cabe recordar que mucho tiempo antes de los profundos análisis sobre el movimiento (Azéma 1992, 2010), el abate Breuil, entre otros, advertía que el caballo galopando del bastón de Teyjat presentaba similitudes con las fotografías animadas de Muybridge (Capitan et al. 1909, 64). Lo mismo se puede decir de Piette, que a la hora de describir el bastón de Lortet vio un ciervo bramando en una escena que comparó a un cuadro (Piette 1904, 156). Resulta imposible recoger aquí todas estas aportaciones ${ }^{1}$,

1 Se puede encontrar un completo estudio de la historia de las investigaciones sobre esta temática en el aná- lisis de Barandiarán (2003). Sigue faltando un trabajo de valoración sobre el concepto de mitograma de Leroi- 
que sin duda han sido clave en la visión que ahora tenemos del arte. Tal y como nosotros lo vemos, no se trata tanto de encontrar la panacea descriptiva del arte paleolítico, como de encontrar un léxico adecuado para especificar algunas de sus características. Es evidente que tratamos de comprender el arte a medida que cambia nuestra visión del mundo. En este sentido, se puede decir que hemos pasado de los símiles con la pintura a los del cine de animación, de los símbolos a los relatos, de la semiótica a un sistema comunicación, y, en definitiva, de un arte considerado primitivo a uno moderno (Fritz et al. 2017, 338-339). En lo que respecta a la narración, deberíamos decir que es un término muy apegado a lo literario, lo cual condiciona en algo su uso, porque nos induce a buscar historias (argumentos) ${ }^{2}$ en vez de centrarnos en el análisis interno de lo visual (puesta en escena). Así se han visto temas sacados de la realidad cotidiana, como una escena de pesca en Gourdan (Tosello \& Fritz 2013, 54) o de mitos, como el del león y el caballo (Barbaza et al. 2017, 364). Algunos investigadores han considerado el arte como una especie de escritura (Anatti 2017, 11), comparándolo con las fábulas de Esopo, constatando el tema del cazador y la presa, e interpretando relatos de migraciones, viajes y una «historia de amor» en Altamira (Anatti 2017, 21 y 22). En lo que se refiere a la puesta en escena, otros autores interpretan ciertas líneas grabadas en torno a los animales como «líneas cinéticas», implicadas en una narración (Luís 2012, 79; 2019). El análisis interno de las escenas, sus tipos, los componentes que la forman, los procedimientos técnicos de la narración, etc., ofrecen una valiosa información sobre el modo de narrar de los paleolíticos (Barandiarán 2003, Fritz et al. 2013). Se ha destacado que la dimensión espacial se puede sugerir a través de la posición de los animales (Tosello \& Fritz 2013, 55), incluso de los sombreados de los cuerpos (Barandiarán 2017, 33). Se ha observado el papel activo del observador en cuevas como Lascaux (Geneste et al. 2003, 71 y 74) o en el arte paleolítico en general (Jelínek 1979, 293). Y que algunas escenas apelan a la imaginación del espectador (Fritz et al. 2013, 39), muestran caballos pastando o ciervos nadando, pero allí no hay ni pasto ni agua (Barandiarán 2017, 35). Estas grafías invitan a participar en el relato, a buscar en la memoria visual la manera de completar lo que no se representa. La narrativa paleolítica es mucho más compleja de lo que sospechábamos en un principio. Por esa razón creemos posible incluir algunos recursos poco habituales de perspectiva o movimientos diversos, que, si bien son raros, podrían formar parte de ese mismo sentido narrativo del que hablamos. Nuestro objetivo final es arrojar algo de luz sobre el sentido de la narración. Para ello hemos creído necesario profundar en sus orígenes.

\section{Fundamentos de LA NARRACión}

Los Homo sapiens llevan unos ciento cincuenta mil años usando la imaginación para contar historias. Estas capacidades no surgen de la noche a la mañana en el albor de los tiempos. A día de hoy, la investigación actual sobre el tema sugiere que estas habilidades cognitivas fueron sustentadas por nuestros antepasados homínidos. En efecto, según indican estos trabajos, recordar experiencias del pasado, imaginar qué sucederá en el futuro (Schacter \& Addis 2009, 108 y 112), pudo ser una ventaja adaptiva considerable a la hora de tomar decisiones vitales para la supervivencia del

Gourhan, que nos explique cómo hemos pasado de asociar a los animales mediante símbolos a valorarlos según los recursos de la puesta en escena, porque esto ha cam- biado, en cierta medida, nuestra manera de ver los paneles rupestres.

${ }^{2}$ A veces, incluso, cuentos (Barandiarán 1993). 
grupo. De no ser así, resulta inconcebible la existencia de la manufactura de útiles, cuya forma ha de planificarse y preverse previamente (Beaune 2008, 18). Sin la imaginación es imposible concebir la materia técnica, que ya desde muy pronto no está reñida con la estética (Beaune 2013). La imaginación, según Leroi-Gourhan $(1971,387)$, formaba ya parte del mundo de los primeros australopitecos. Este imaginario se puede relacionar con la capacidad para revivir o recordar eventos pasados e imaginar posibles futuros (Corballis 2013, 1; Dissanayake 2017, 90), es decir con las capacidades narrativas del sistema de comunicación homínido (Tomasello 2013, 206-207). Es posible que nuestros parientes homínidos utilizaran un lenguaje de gestos y sonidos para comunicar, por ejemplo, la presencia de un animal mediante la imitación de su voz. Incluso la presencia de fauna consumida (posiblemente carroña) en los yacimientos permite plantear la posibilidad de que los homínidos pudieran haberse adelantado a los carnívoros, gracias al descifrado de las huellas (Mithen 1998, 113). Nos interesa mencionar esta hipótesis porque las huellas son señales visuales con un alto contenido narrativo. No solo nos aportan información sobre la especie en cuestión o si se prefiere, en términos narrativos, del actor de la escena, sino que además son un importante referente temporal. Pues son señales de los animales que han pasado, es decir de un hecho ocurrido en el pasado, que puede intentar reconstruirse mentalmente. Además, son indicadores del futuro, de dónde estarán las presas. En ese sentido las huellas son narrativas, pues cuentan lo que ha pasado e incluso pueden indicar lo que pasará. No solo eso, pueden indicarnos una acción transcurrida en un lugar concreto, un grupo que se para a beber en un río, animales que se desplazan con sus crías en una migración o son perseguidos por un depredador... Sin embargo, es obvio que esas acciones ya han transcurrido, solo la imaginación puede recrearlas a partir de la forma, el tamaño y la posición de las marcas en el suelo. Por lo tanto, la huella gráfica tiene todos los componentes fundamentales de la narración. Resulta difícil creer que al menos algunas de estas nociones escaparan por entero a las capacidades cognitivas de los homínidos, sobre todo si, como se supone, eran capaces de interpretar huellas (Avital 1998, 8). Las comunidades cazadoras-recolectoras saben descifrarlas de un modo sorprendente para quienes hemos nacido en ciudades asfaltadas, porque desde niños aprenden a reconocerlas e interpretarlas (Patte 1960, 37). Si se elaboran historias en torno a las huellas, es porque las huellas en realidad cuentan historias de sucesos reales ocurridos en el tiempo (Pastoors et al. 2015).

La narración de lo visual debió de ser una actividad muy temprana, pues había imágenes naturales que tenían un gran potencial narrativo, incluso para los homínidos. Claro está que todo ello está determinado por el sistema perceptivo humano, que cada vez prestaba mayor importancia a lo visual (Helvenston \& Hodgson 2010, 61). La visión del horizonte adquiere especial relevancia en los primates terrestres, cuando abandonan los árboles y aparecen ante ellos nuevos entornos, caracterizados por las infinitas extensiones del espacio. En resumen, se incentivaron las actitudes básicas de la observación y la descripción del espacio, en base a la posición bípeda, configurándose así un «mundo visual erecto» (Gibson 1974, 205). Sin este mapa conceptual, la percepción de la realidad sería inabarcable (Bickerton 1994, 40). Sirvan estos ejemplos tan solo para constatar que la narración se asienta bajo unos parámetros fijados por la percepción visual. Esta es una de las razones por la que las sociedades orales, no suelen separar drásticamente el arte visual del relato oral. Las mujeres Wankamadla ilustran su narrativa en la arena (Davidson 2013, 23), las muchachas inuits hacen lo mismo en la nieve (Aldea 1991, 187) y los walbiri australianos cuentan historias sin emplear palabras, tan solo haciendo dibujos (Freedberg 1992, 80). Las imágenes cuentan historias, las historias se cuentan con imágenes, se pueden contar historias sin imágenes, pero entonces estás son evocadas de inmediato en nuestra mente. 


\section{Aspectos poco comunes de la puesta en escena}

\subsection{Desde atrás}

En el arte paleolítico se han reconocido algunos raros ejemplos de animales representados de espaldas. EEstarían dentro o podrían ser considerados como el reverso de los animales frontales vistos de cara? Esto podría suceder en una de las cabras en "perspectiva de huida» de Niaux, que Breuil describió como "cabra huyendo vista de espaldas» (Beltrán et al. 1973, 190). En un fragmento óseo de Laugerie-Basse, con un extraño animal grabado, descrito como una «especie de insecto obeso» con antenas (Girod 1900, 10, pl. XXII. 3); pero que ha sido identificado como una cierva o cabra vista de frente por detrás (Breuil 1907, 397, fig. 3. 6). Ambas lecturas fueron recogidas en el catálogo Reinach, aunque la primera entre interrogantes (Reinach 1913, 88). Igualmente, Luquet identifica una cabra vista de espaldas, con las patas replegadas como si estuviera tumbada (Luquet 1928, 94). Y en una azagaya de punta fracturada del sitio de La Vache, se ha reconocido un cérvido en vista dorsal sin cara, observándose la posibilidad de que existan algunos otros casos similares (Welté 2003a, 125). El resto de grafías que hemos podido recopilar, están asociadas, y en su mayoría forman parte, de una composición escénica (fig. $1 \mathrm{C}, \mathrm{D}, \mathrm{E}, \mathrm{G}$ y H). Por ejemplo, sobre un fragmento de hueso de bisonte de Enlène, alguien tan poco dado a reconocer escenas como Bégouën, admitía que los animales representados estaban relacionados en una acción conjunta, en concreto se trataba de unas aves que rodeaban a un saltamontes (el cual era el centro de la acción). Sin embargo, no explicó la presencia en este escenario de dos grafías indeterminadas que, según Kühn, eran dos gatos salvajes vistos en gran parte desde atrás (Bégouën 1929, 139); pero que parecen más bien búhos (Barandiarán 2006, lám. 31). Otra escena compleja de temática indiscernible, en la que se ha creído ver las partes dorsales de los animales, es un fragmento de bastón en asta de reno proveniente de Gourdan (fig. $1 \mathrm{D}$ y H). Según advierte Piette, el bóvido de la parte superior izquierda ha sido realizado como si fuera visto desde atrás, es más, también señala que uno de los "antílopes» de la parte inferior, gira la cabeza para mirar atrás (Piette 1907, 96). Esta afirmación parece algo atrevida; sin embargo, da qué pensar si se comparan: por un lado, las semejanzas de este bóvido con el de la famosa «escena de iniciación» de La Vache (fig. 1 E), y por otro, con otros giros similares de cabeza, como ocurre con una cierva grabada en una placa de piedra caliza de Bout du Monde (fig. 1 G). En este último caso se ha creído ver una cierva corriendo con su cría (Alcalde et al. 1911, 225), pero la cierva no tiene ojos, ni nariz, ni boca, lo cual no es raro de ver en el arte paleolítico, sobre todo en figuras esquemáticas, pero esta no lo es. Además, no solo se trata de una omisión de los rasgos faciales, sino es que ni siquiera tiene delimitada la cara. En los casos de los bóvidos, incluso se ha representado el pelaje de la parte trasera (fig. $1 \mathrm{D}$ y E) y en las grafías indeterminadas de Enlène, una fina línea de puntos parece señalar la nuca (Bégouën 1929, 193). La posición de espaldas es muy rara, pero se encuentra también en las pinturas prehistóricas del río Jinsha (China), en un lugar tan alejado en la distancia como cercano a las propuestas naturalistas del arte paleolítico europeo (Taçon et alli 2010, 77, 79 y 82). Para terminar este extraño repertorio de animales hechos de espaldas, Aujoulat y Gély mencionan un búho de la cueva Chauvet con el cuerpo visto por detrás y la cabeza de frente (Clottes 2010, 95), espectacular giro de cabeza que solo pueden hacer los búhos ${ }^{3}$.

3 Posiblemente un búho real (Bubo bubo) o búho chico (Asio otus) por los característicos penachos en forma de orejas que alberga encima de la cabeza (Braun 2018 , 14). Las aves estrigiformes tienen una visión frontal (binocular) excelente; aunque no pueden mover los ojos, motivo por el que se ven obligados a girar la cabeza, lo cual pueden hacer hasta $270 .^{\circ}$. Otras aves tienen los ojos ubicados en los lados de la cara, razón por la cual tienen una peculiar manera de mirar de frente con un solo ojo (fig. 2 E 14). 

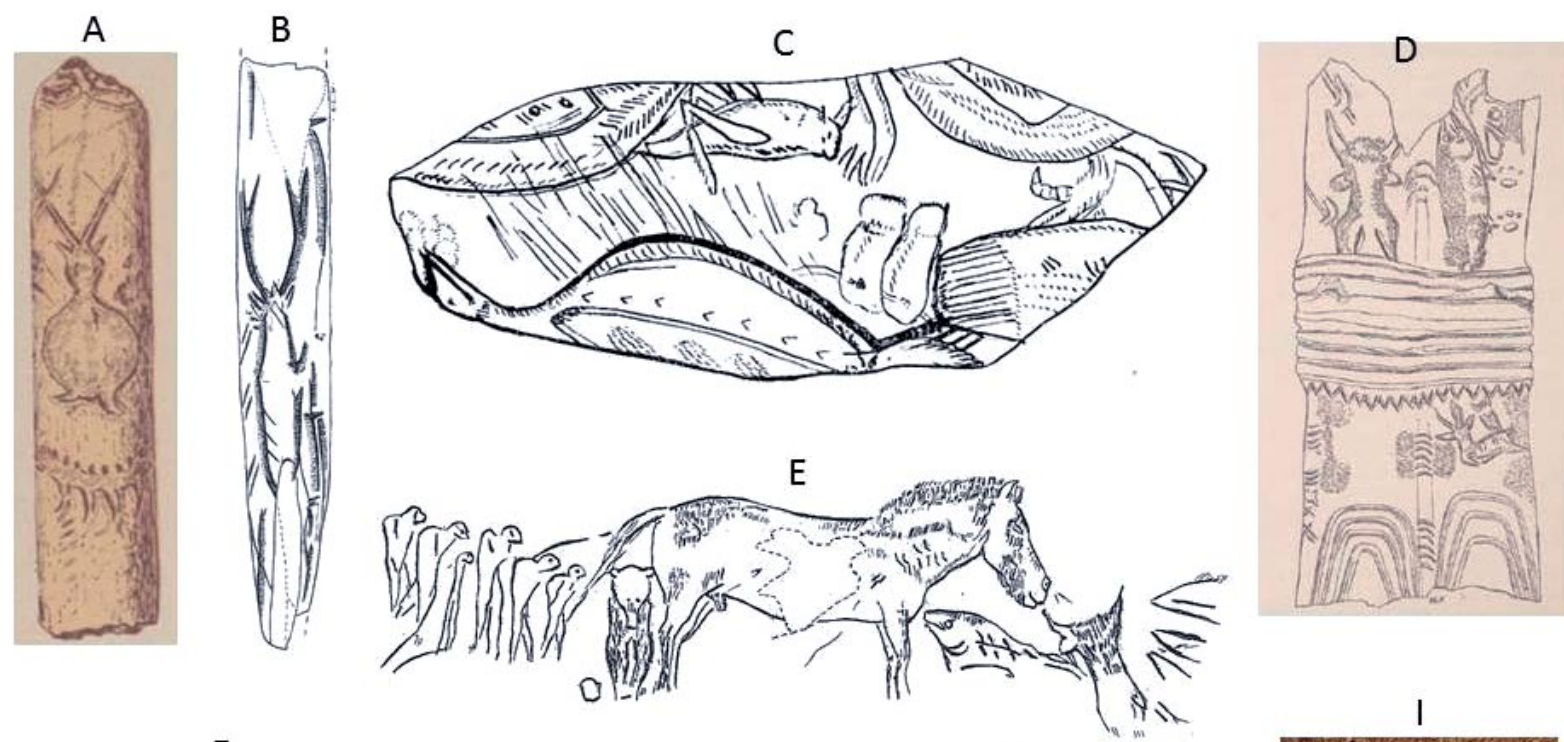

$\mathrm{F}$

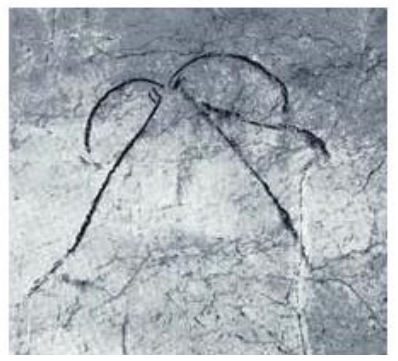

G

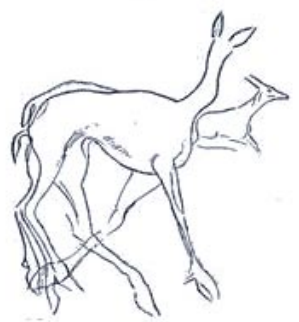

$\mathrm{H}$

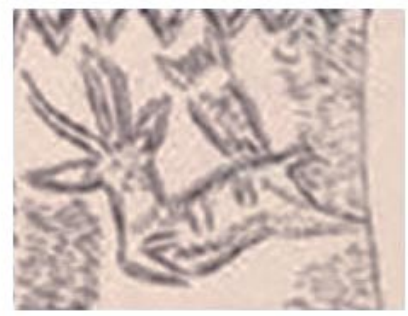

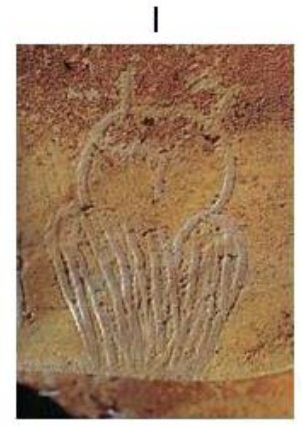

Figura 1. A Laugerie-Basse (Girod 1900, pl. XXII. 3). B La Vache (Welté 2003a, 125, fig. 99). C Enlène (Bégouën 1929, fig. 1). D Gourdan (Piette 1907, fig. 112). E La Vache (Delporte 2003b, 361, fig. 452). F Niaux (Beltrán et al. 1973, fig. 128). G Bout du Monde (Alcalde et al. 1911, fig. 222). H Detalle Gourdan (Piette 1907, fig. 112). I Chauvet (Clottes 2010, fig. 89).

\subsection{De frente}

Al margen de las representaciones de cápridos en perspectiva frontal (Barandarián et al. 2013), existen figuras en posturas similares que no forman parte de este conjunto iconográfico. Por un lado, hay un grupo de cabezas frontales (fig. 2 A) y por otro, un diminuto repertorio de cabezas y cuerpos frontales (fig. 2 B). Además, se pueden añadir las grafías animales de cabezas frontales y cuerpo de perfil, es decir las que giran la cabeza para mirar de frente (fig. 2 C). Estas últimas, expresan el giro de cabeza inverso al descrito por Piette, mediante el uso de una perspectiva combinada, lo que las distingue de las otras dos. El primero y segundo grupos mantienen una perspectiva frontal única, pero en diferentes formatos. Incluso hay casos muy especiales en los que se ha representado el cuerpo en posición frontal y la cabeza de lado (fig. 2 D). Pero, aparte de estas excepciones, lo normal es que las grafías frontales miren de frente, aunque hay alguna que no tiene cabeza y otras han sido hechas sin ojos. Teniendo en cuenta esto, podemos decir que uno de los aspectos que mejor caracterizan a las grafías frontales, tiene que ver con la puesta en escena, pues casi todas 
miran de frente al supuesto espectador que las contempla, es decir, aluden a un escenario que está fuera del espacio gráfico que ocupan. La consecuencia directa de esta evocación es que al mirar directamente al sujeto de la visión, se establece una conexión entre el objeto y quien lo contempla. De esta forma, se puede decir que la mirada del observador interviene en el transcurso de la acción, pues es como si el animal que gira la cabeza para mirarnos se diera cuenta de que está siendo observado. El efecto que produce este cruce de miradas es de un realismo enorme, porque es lo que sucedería si al encontrarnos con un animal, nuestra presencia fuera advertida por algún tipo de ruido. De manera gráfica, se logra incluir virtualmente al observador como la causa más probable de la reacción del animal. Un ejemplo de esto que estamos diciendo nos lo ofrece una cabra tumbada de Ekain, que vuelve la cabeza "hacia quien la contempla» (Altuna \& Apéllaniz 1978, 28), ya que algo situado en nuestro eje de visión parece llamar la atención de la cabra, mientras descansa con una pata extendida y la otra recogida bajo el cuerpo. En general este tipo de grafías aparecen aisladas (fig. 2 E) y suelen interpretarse como animales en alerta o en actitud de escucha (Azéma 2010). De este repertorio destacan los búhos y lechuzas, a los que siempre se les representan los ojos (fig. 2 E 11, 12, 13 y G 19). Pero también hay algunos casos de asociaciones homoespecíficas, que vinculan este recurso expresivo con las escenas grupales. Se observan dos tipos de asociaciones homoespecíficas, unas en las que solo uno de los animales mira de frente (fig. $2 \mathrm{~F}$ ) y otras, exclusivas de Trois-Frères, en las que todos miran de frente (fig. $2 \mathrm{G}$ ).

En las asociaciones homoespecíficas en las que tan solo uno de los animales mira de frente, como en los casos de La Vache y Limeuil (fig. 2 F 15, 16 y 17), la mirada frontal es un recurso que aporta credibilidad y viveza a la escena. Es decir, sirve para que la escena creada se parezca a un suceso acontecido en la realidad. Crear un suceso no es una labor fácil, los paleolíticos lo consiguieron usando trucos que daban la sensación de realismo. En la vida real muchas acciones pueden desarrollarse al mismo tiempo, los artistas paleolíticos quisieron emular esto mismo gráficamente, ideando un escenario donde los animales actuaban de maneras diversas. Sobre dos fragmentos de una costilla de La Vache, se grabaron dos bisontes marchando de lado y un tercero mirando de frente (Welté 2003b, 318). En el mismo yacimiento, un alisador fue grabado con cuatro osos (Delporte 2003a, 293), uno de los cuales tiene la boca abierta en actitud de bramar, mientras otro parece mirar de frente (Barandiarán 2003, 124). Y en una placa caliza de Limeuil se grabaron cinco renos o cérvidos, cuatro de ellos en actitudes diferentes: uno galopando, otro marchando, otro mirando de frente y un último retrospiciente (Tosello 2003, 124 y 125). En los ejemplos mencionados, la actitud de la grafía que mira de frente se combina con otras distintas (galopando, marchando, ¿bramando?, escuchando), en una misma composición escénica. Diversos comportamientos suceden en un mismo espacio y tiempo. En definitiva, lo que se está tratando de reflejar aquí es la simultaneidad de un hecho simulado de la realidad o lo que es lo mismo, la sincronía.

En las asociaciones homoespecíficas en las que todos los animales miran de frente, las miradas producen un efecto bastante distinto (fig. 2 G 18 y 19). En la cueva de Trois-Frères, dos lechuzas $\mathrm{y}$ dos felinos fueron representados mirando de una forma que podría calificarse de intimidatoria (Bégouën \& Breuil 1958, 11). En estas ocasiones, la mirada parece tener un significado de amenaza, sobre todo en lo que concierne a unos depredadores tan temibles como los felinos. Además, el grabado de los ojos de los felinos se ha exagerado de tamaño y forma para resultar más llamativos (fig. 2 G 18). Se han representado incluso las pupilas mediante dos círculos concéntricos, algo que también ocurre en algunas grafías de cabezas humanas frontales de la región pirenaica, como Marsoulas, Ker de Massat y Labastide (fig. 2 A 1). 

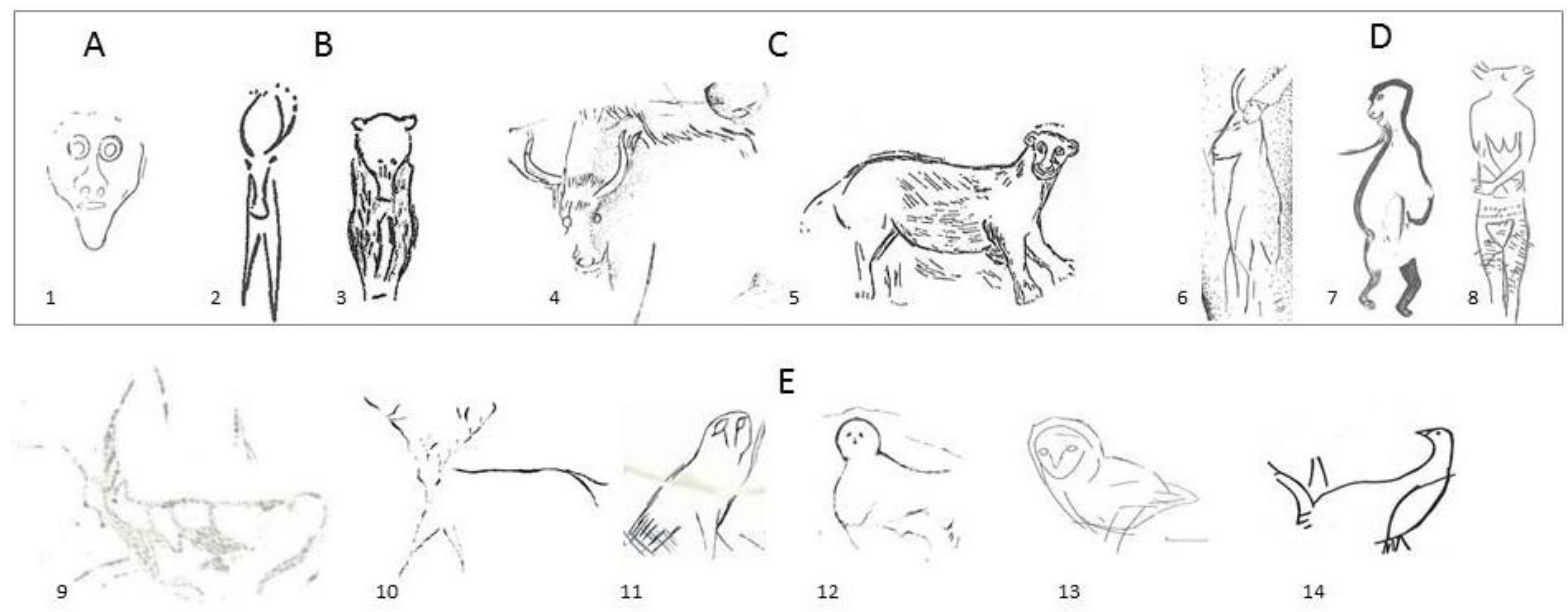

E
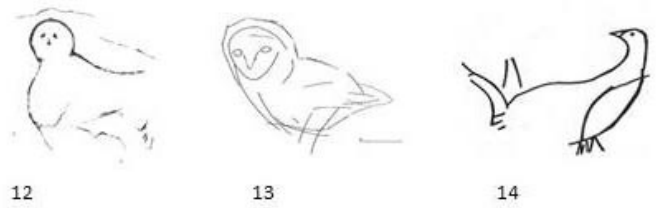

14

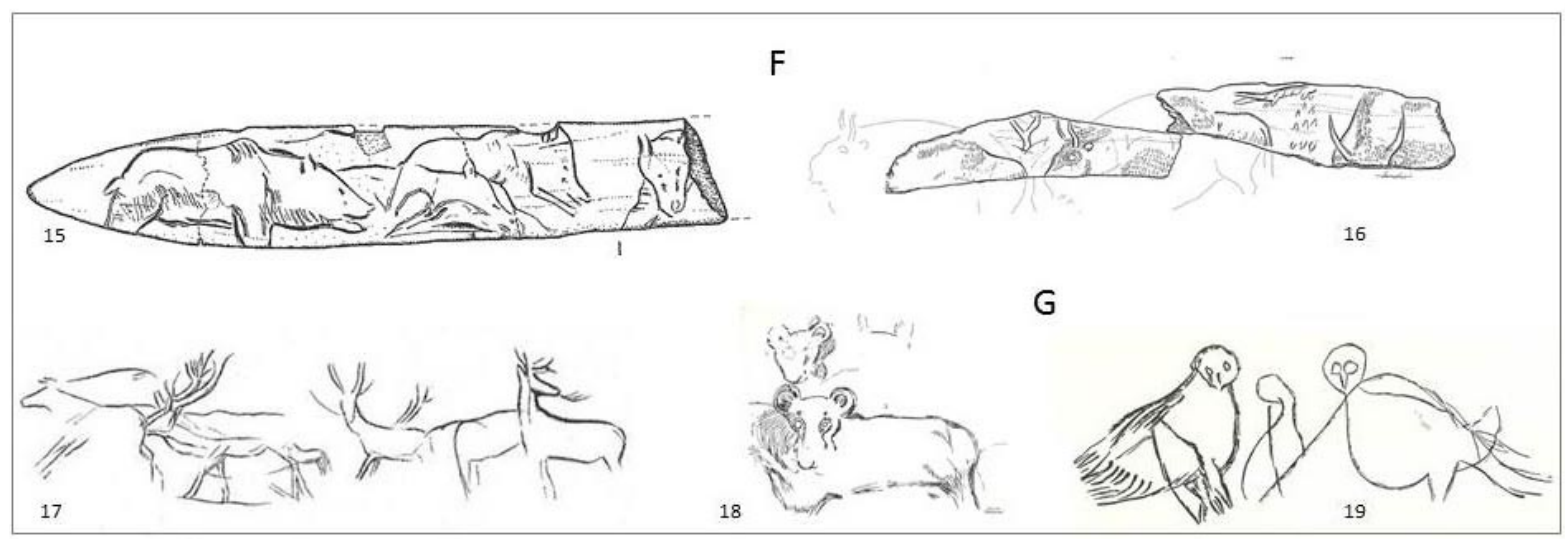

Figura 2. A 1 Cabeza frontal Labastide (Omnes 1984, 22, pl. 3). B 2 Gourdan (Piette 1904, 159, fig. 52), B 3 La Vache (Roussot 1979, 84, fig. 44. 6). C 4. Combarelles II (Azéma, 2010, 161, fig. 65), C 5 TroisFrères (Bégouën \& Breuil 1958, 10, fig. 2). D 6 La Vache (Buisson 2003, 407, fig. 507), D 7 Le Portel (Breuil \& Jeannel 1955, pl. VII. 23), D 8 Tolentino (Massi et al. 1997, 33, fig. 6). E 9 Ekain (Altuna \& Apellaniz, 1978, 28, fig. 7), E 10 Bayol (Drouot 1953, 404, fig. 8), E 11 Marsoulas (Fritz \& Tosello 2007, 28). E 12 Le Portel (Brenil \& Jeannel 1955, pl. VI. 2), E 13 Margot (Pigeaud et al. 2012, 91, fig. 11. A. 74). E 14 Teufelsbrücke (Kozlowski 1992, pl. 57). F 15 La Vache (Delporte 2003a, 293, fig. 348). F 16 La Vache (Welté 2003, 318, fig. 382). F 17 Limeuil (Tosello 2003, 125, fig. 71). G 18 Trois-Frères (Bégouën \& Breuil 1958, 11, fig. 3), G 19 Trois-Frères (Bégouën \& Breuil 1958, 17, fig. 16).

\subsection{Desde arriba, ¿existe la perspectiva cenital?: el caso de las serpientes en el arte paleolitico}

Leroi-Gourhan $(1984,136)$ hizo una clasificación de la perspectiva según los ángulos de visión. Según su terminología la perspectiva bi- o pluri-angular opuesta, es decir, la visión desde arriba, no se da en el arte paleolítico. Sin embargo, se han apuntado algunos casos concretos que quizás pudieran estar aludiendo a este tipo de visión desde lo alto, como las focas de Nerja (Pérez \& Raga 1998, 126) o quizás un glotón en Saulges (o Lorthet) (Barandiarán 1972, 351, fig. 5; 1974, 185). No solo eso, sino que parece lógico pensar que algunos modelos representados son vistos y concebidos así debido a: ser animales que reptan o están tumbados en el suelo, nadan bajo el agua, o, ser 


\begin{tabular}{|c|c|c|c|c|}
\hline YACIMIENTo & SOPORTE & TÉCNICA & Periodo & Bibliografía \\
\hline Altxerri & Parietal & Grabado & Magdaleniense & Altuna \& Apellániz 1976, 128, fig. 71 \\
\hline Ardales & Parietal & Grabado (incisión) & Solutrense & Espejo \& Cantalejo 2006, n. ${ }^{\circ}$ 539. IV.B.35a. 2 \\
\hline Gourdan & Fragmento de hueso & Grabado & Magdaleniense superior & Chollot 1964, 93 \\
\hline Lespugue & $\begin{array}{l}\text { Fragmento de hueso } \\
\text { (bóvido) }\end{array}$ & Grabado profundo & $\begin{array}{l}\text { Magdaleniense medio/ } \\
\text { superior }\end{array}$ & Saint-Périer 1924, 11, fig. 4 \\
\hline Llonín & Parietal & Pintura roja & Gravetiense/Solutrense & Barbaza et al. 2017, 356, fig. 466 \\
\hline Lortet & Asta de reno & Ligero relieve & Magdaleniense & Piette 1874,305 \\
\hline Madeleine $/ \mathrm{La}^{4}$ & $\begin{array}{l}\text { Asta de reno (bastón } \\
\text { perforado) }\end{array}$ & Grabado & $\begin{array}{l}\text { Magdaleniense } \\
\text { medio }\end{array}$ & Piette 1907, pl. XXVII, fig. 198 \\
\hline Madeleine/La & $\begin{array}{l}\text { Asta de reno (bastón } \\
\text { perforado) }\end{array}$ & Grabado & Magdaleniense & Girod 1906 \\
\hline Malta & Placa de marfil & Grabado & Gravetiense & Abramova 1995, 52 \\
\hline Montgaudier 5 & Bastón perforado & Grabado & $\begin{array}{l}\text { Magdaleniense } \\
\text { superior }\end{array}$ & Breuil \& Saint-Périer 1927, fig. 68. 2 \\
\hline Niño/El & Parietal & Pintura roja & Gravetiense/Solutrense & Gárate \& García 2011, 25, figs. 6e y f \\
\hline Pendo/El ${ }^{6}$ & $\begin{array}{l}\text { Hueso (costilla de } \\
\text { herbívoro) }\end{array}$ & Grabado & $\begin{array}{l}\text { Magdaleniense } \\
\text { final }\end{array}$ & Barandiarán 1973, 197-198, figs. 14 y lám. 47.3 \\
\hline Pendo/El ${ }^{7}$ & $\begin{array}{l}\text { Asta de ciervo (aza- } \\
\text { gaya) }\end{array}$ & Grabado & $\begin{array}{l}\text { Magdaleniense } \\
\text { final }\end{array}$ & Barandiarán 1973, 191, lám. 18. 1. \\
\hline Pila/La & Arpones & Grabado & $\begin{array}{c}\text { Magdaleniense } \\
\text { superior/final }\end{array}$ & González Sainz 1989, figs. 20. 16 y 22.5 \\
\hline Tito Bustillo & Parietal & $\begin{array}{l}\text { Piqueteado con man- } \\
\text { chas de color negro }\end{array}$ & ¿Gravetiense? & Balbín et al. 2003, 100, fig. 13 y 101, fig. 14 \\
\hline Tuc d'Audoubert & Parietal & Grabado & Magdaleniense & Bégouën et al. 2009, 72, fig. 50 y 51 \\
\hline Valle & Punzón & Grabado & Magdaleniense final & Barandiarán 1973, 237, lám. 18. 2 \\
\hline
\end{tabular}

Se han visto serpientes en el arte mueble (casi siempre en soportes estrechos) de Laugerie-Basse (Cartailhac 1864, 299, fig. 104; Girod 1900, 97 , pl. II, 2, pl. XIV, 2), Mas d'Azil (Piette 1907, XLIII, 1), Madeleine (Capitan \& Peyrony 1928, 104), Mouthiers (Luquet 1926: 155-156), Placard (Reinach 1913, 170, fig. 1. 9), Plaglicci (Leonardi 1988, 170, fig. 61. 2), Teyjat (Capitan et al. 1906, 207, fig. 70. 1, Capitán et al., 1909,63 y 64, fig. 4), algunas de ellas, por diferentes motivos, imposibles de identificar.

En el arte parietal se vincula con los trazos hechos sobre arcilla blanda de cuevas como Rouffignac, Ardales o líneas sinuosas pintadas, como las de Pileta (Breuil et al. 1913, 24 y 41), y sus formas esquemáticas (y esto sucede también en los soportes mobilares), meandros, espirales y zig-zags.

\section{Figura 3. Cuadro de serpientes del arte paleolitico europeo.}

4 Serpiente de cuerpo muy grueso y cabeza diferenciada y picuda. Cola estrecha y más o menos larga, adornada con cortos trazos exteriores. Estos trazos podrían representar la aleta anal de algunas anguilas. Piette identifica una serpiente o un congrio (Piette 1907: pl. XXVII, fig. 198), Reinach la recoge como posible anguila (Reinahc 1913, 137, fig. 1.1), Redou la clasifica como serpiente (Redou 2006, 90, tabla 1 y 95, fig. 5. 6), Barandiarán como anguila o serpiente (Barandiarán 2006, 185, fig. 70).

5 Serpientes o anguilas (Barandiarán 2006, 185, fig. 70). Por el contexto grafico podría ser una serpiente acuática. Por la forma de la cabeza, y las manchas de la piel (zig zags, líneas verticales), coincide con el de algunas culebras viperinas (Natrix maura), pero esta serpiente no soporta latitudes tan septentrionales como la culebra de collar (Natrix natrix). Ambas son buenas nadadoras y buceadoras (Gruber 1999, 133, 134 y 138).

6 Serpiente asociada a caballo (Corchón 1986, 429, fig. 166. 1). Véanse también los serpentiformes sobre fragmentos de asta de ciervo de la cueva de Camargo (Corchón 1986, 413, fig. 153). Estas y otras estilizaciones podrían ser, en definitiva, signos que expresan simbólicamente a los animales (Corchón 1981, 48).

7 Clasificada como serpentiforme, junto con otras grafías grabadas sobre azagayas, arpones y varillas 
marcas dejadas en la superficie terrestre como las huellas. Los aborígenes australianos nunca representan las huellas de perfil, sino tal y como están acostumbrados a verlas, desde arriba (Lorblanchet 1978, 153). Lo mismo se ha apreciado en las serpientes, según algunos autores parecen haber sido representadas desde arriba o proyectadas en sentido vertical (Deffarge et al. 1975, 23; Barrière 1982 , 155). Sobre un fragmento de costilla, probablemente perforado en uno de sus extremos, se grabaron en trazo profundo dos serpientes de cabeza cordiforme, en las que parecen haberse indicado las placas cefálicas (Saint-Périer 1923, 12). Lo mismo ocurre en otro posible colgante, elaborado en asta de reno del sitio de Lortet, donde se grabó una serpiente, esta vez en posición estirada, con la cabeza bien diferenciada del cuerpo, con dos líneas simétricas que señalan, como en Lespugue, la cabeza vista desde un ángulo bastante elevado, tal y como las solemos ver los seres humanos. El repertorio de serpientes naturalistas es limitado (fig. 3), a partir de ciertos casos en los que se pueden identificar claramente el resto se ha supuesto una desviación o simplificación del modelo natural (Barandiarán 2017, 41-42). Y, aparte de que en ocasiones resulta muy difícil aceptar ciertos signos sinuosos, meandros, zig-zags o serpentiformes como formas esquematizadas o, como diría Breuil, «degenereradas» de serpientes, lo cierto es que los seres humanos poseemos un sentido innato para captar sus movimientos (Isbell 2005, 11). Las serpientes y los mamíferos placentarios comparten un pasado evolutivo como depredador y presa. Parece razonable suponer que parte del sistema visual de los primates arborícolas se especializó en la detección de este depredador venenoso (Isbell 2005). Lo que explica que algunos primates hayan desarrollado de forma innata, todo un lenguaje, o como algunos autores prefieren decir, un sistema de representación, en torno a ellas (Bickerton 1994, 40). Quizás también explique la tendencia, verdaderamente inverificable, de algunos prehistoriadores a considerar algunos trazos sinuosos como hipotéticas serpientes (Breuil et al. 1913, 24 y 41; Barrière 1982, n. ${ }^{\circ}$ 52, 54, 161, 162, 163 y 164), o por el contrario, pueda ser un argumento a favor de la simplificación de un modelo original, que tanto por su asimilación visual biológica, como por su perspectiva natural plana, tiende a la simplificación y el esquematismo de las formas. De hecho, algunas sociedades orales como los pigmeos, representan a la serpiente con un simple trazo sobre el suelo (Chevalier \& Gheerbrant 1986, 925).

La perspectiva cenital en la experiencia visual humana está determinada por nuestro ángulo de visión, pues solo en determinadas circunstancias podemos ver a los cuadrúpedos desde arriba; sin embargo, los animales pequeños que se desplazan por el suelo o el agua son percibidos de manera habitual por debajo de nuestro ángulo de visión. En el primer caso tenemos los cuadrúpedos representados desde un punto de vista aéreo, imposible en circunstancias habituales, a menos que estén tumbados cerca, como parece que se representaron dos bóvidos, uno sobre soporte óseo de La Madeleine (Roussot 1997, 84, fig. 44. 13) y un fragmento de varilla semicilíndrica de Laugerie-Basse (Cartailhac \& Breuil 1907, 33 fig. 13. e). El resto de animales vistos desde arriba son pequeñas especies que suelen desplazarse por debajo de nuestro ángulo de visión o bien pueden verse a través del agua de los ríos. Sobre una punta de azagaya de Fontalès se observa una asociación homoespecífica de tres ranas, dos de ellas quizás estén implicadas en una escena de acoplamiento (Bosinski 2011, 47), la tercera ha sido representada completa, con dos ojos y la convención de los paréntesis paralelos invertidos que hemos podido también apreciar en las cabezas de serpientes. Estos pa-

de La Pila, Pendo y Valle (Barandiarán 1994, 51, fig. 1-5), recogemos este caso, que con la cabeza triangular (con quizás representación de la lengua) diferenciada del cuerpo, la cola alargada y puntiaguda, responde bien a la morfología anatómica de Colúbridos o
Vipéridos (Bruno \& Maugeri 1992, 29-31). Además, el cuerpo del animal refleja bien el movimiento ondulatorio de la serpiente cuando se desplaza horizontalmente (serpenteo horizontal, mucho más frecuente que el lateral). 
réntesis están también sobre la cabeza de un pez de Laugerie-Basse (Roussot 1997, 84, fig. 44. 16) y quizás puedan entenderse como un recurso para expresar la perspectiva cenital. Sobre un fragmento óseo de Teyjat se grabó una foca en el momento de saltar al agua (Capitan et al. 1906, 210), cuya parte delantera es simétrica, con los mostachos a ambos lados de la cara y sendas aletas dorsales. El resto del repertorio lo completan animales pequeños como una posible mariquita hecha sobre sesamoideo de reno en Laugerie-Haute (Giraux 1907, 213, fig. 3), un posible batracio en Petersfels (Bosinski 2011, 51), un anfibio asociado a un nenúfar en La Madeleine (Bosinski 2011, 51) o la salamandra sobre cornamenta de reno en Laugerie-Basse (Redou 2006, 95, fig. 5. 1).

La representación cenital ofrece a menudo una figura plana, que la acerca al esquematismo, como se observa en el bóvido de Laugerie-Basse (Breuil 1907, fig. 4), o incluso en la posible representación de una piel animal en Mas d'Azil (Breuil 1907, fig. 2. 11), como si estuviera tendida en el suelo o, como hacían hasta hace poco los inuit, que las estacaban en la nieve (Aldea 1991, 63, fig. 43 y 97). Además, esta perspectiva no es extraña en el arte esquemático (Romero 2010, 522) o en la iconografía celtibérica (Blanco 1997, 187).
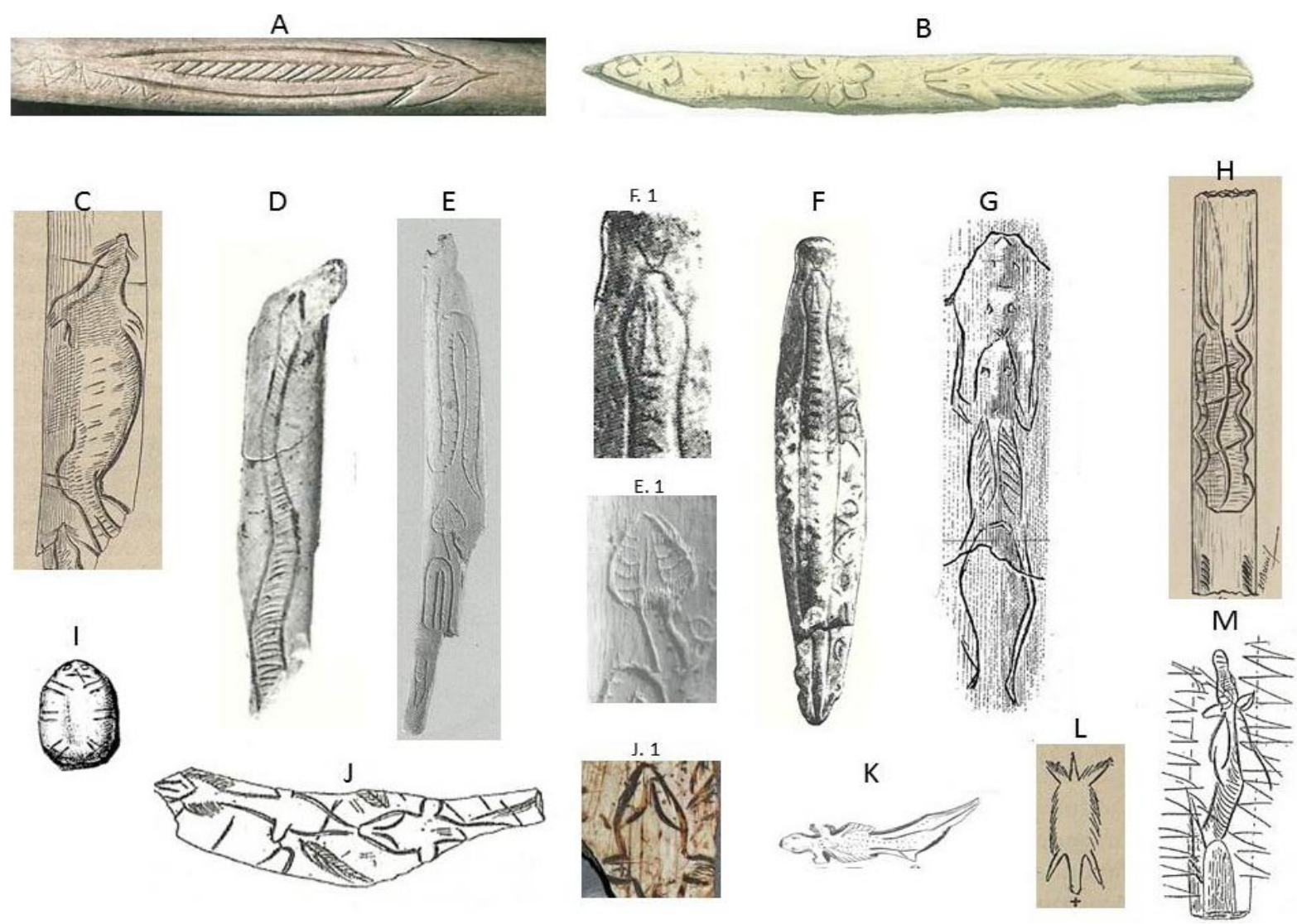

Figura 4. A Petersfels (Bosinski 2011, 51). B La Madeleine (Bosinski 2011, 51). C (Capitan et al. 1906, 209, fig. 71. 2). D Gourdan (Chollot 1964, 92, 47304). E Lespugue (San Juan-Foucher \& Vercoutère 2014, 125, fig. 15). F Lortet (Chollot 1964, 136, fig. 47418). G Fontalès (Darasse \& Guffroy 1960, fig. 15). H LaugerieBasse (Breuil 1907, fig. 4.5). I Laugerie-Haute (Giraux 1907, 213, fig. 3). J Laugerie-Basse (Roussot, 1997, 84, fig. 44. 16). K Laugerie-Basse (Roussot 1997, 55, fig. 28. 16). L Mas d'Azil (Brenil 1907, fig. 2. 11). M La Madeleine (Roussot, 1997, 84, fig. 44. 13). 


\section{Sonidos y otros efectos de la puesta en escena}

La narración en el mundo oral presta mucha atención a los sonidos que hacen los animales. Esto se observa en los cantos de numerosos pueblos cazadores-recolectores que imitan las voces de los animales. El sonido del pez en el agua, el ruido de la ballena, el bramido del toro o los pájaros entre otros muchos son aludidos e imitados en sus canciones (Bowra 1984, 73, 266, 89 y 250). Por ejemplo, un pigmeo del Gabón canta la siguiente estrofa: «El pez hace... ipif./ el pájaro hace ¡viss!/ la marmota hace ignan!» (Trilles 1931, 237). Las onomatopeyas son una figura retórica consistente en el empleo de palabras que imitan sonidos, es decir son un recurso narrativo, no solo empleado en canciones, sino en cuentos y mitos trasmitidos de forma oral. Y mucho más, la mayoría de los pueblos ágrafos aprenden a reconocer e imitar las voces de los animales desde niños porque les va la vida en ello. De esta forma, los bosquimanos del Kalahari conocen los gritos de alarma de las aves, porque revelan la presencia de serpientes que rondan por el campamento (Silberbauer 1983 , 100). O imitan, como los cazadores inuits, el sonido de la orca para alejar de sus kayaks a las peligrosas morsas (Hernando 1992, 54). El oído de estas gentes está repleto de información procedente de múltiples sonoridades del entorno natural. Es en la vida cotidiana donde se fabrican las experiencias auditivas que irán unidas a los relatos. Podemos decir, sin temor a equivocarnos, que los sonidos de los animales forman una parte relativamente importante de la narrativa oral.

Presumiblemente, los sonidos de los animales eran reconocidos e imitados de forma muy parecida por los paleolíticos. Al menos esto es lo que algunos ejemplos del arte parecen constatarnos, pues reflejan sin duda a los animales en actitud de emitir sonidos (fig. 4). Uno de los primeros en advertirlo fue Piette, en una cabeza esculpida de un caballo relinchando de Mas d'Azil (Piette 1904, 143) y en un reno (en realidad un ciervo) grabado sobre un bastón de asta de Lortet (fig. 4 B). Este reno gira la cabeza y emite un sonido para llamar a su cría (Piette 1904, 158); pero allí no hay cría alguna. De estar en algún sitio, la causa del bramido del reno, sería fuera del encuadre. Una lectura reciente interpreta los rombos que se ubican por encima de las cabezas de los ciervos como un arma arrojadiza tipo boomerang, por lo que el animal retrospiciente "parece mirar aterrado al peligro que le acecha» (Utrilla \& Bea 2006-07, 164). Sea como fuere, con la mirada o mediante el sonido, el ciervo en cuestión parece aludir a un elemento no representado gráficamente. Lo mismo se observa en uno de los dos ciervos en actitud de berrear de la cueva Candamo, con seis posibles lanzas clavadas en el cuerpo y que ha sido representado «volviendo la cabeza hacia atrás como mirando a los cazadores, que le han clavado numerosos venablos» (Hernández Pacheco 1919, 65); pero allí no hay cazador alguno. El sonido que se supone emiten estos y otros animales en asociación es fruto de una consecuencia cuya causa ha de imaginarse $y$, en ocasiones, un recuso narrativo que relaciona a los personajes en una escena conjunta. Esto puede observarse en una plaqueta de Parpalló con un ciervo macho grabado en actitud de berrea (fig. 4 D), en asociación a una cierva con el rabo levantado, en actitud receptiva, en lo que se supone es una escena de preacoplamiento otoñal (Villaverde 1994, 198, fig. 13).

Así se transcribe visualmente la temporalidad o, dicho de otro modo, se construye el tiempo en el que ha de ser enmarcado el relato. La berrea de los ciervos, por ejemplo, nos ubica automáticamente en el periodo otońal, pues para alguien que vive diariamente en contacto con estas experiencias sonoras, las voces de los animales tienen claras connotaciones estacionales. La destacada habilidad para sugerir el sonido por medio de la imagen tiene su culminación en algunos signos que se

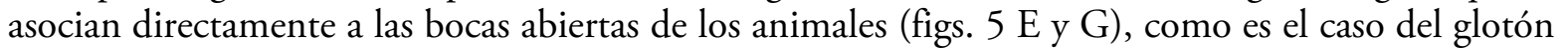
de Casares (Barandiarán 1974, 191), el ciervo de Abauntz y Fontalès (Utrilla \& Mazo 2011, 36, fig. 8), o ciertos animales de Foz Côa (Luís 2012, 73, fig. 3; 2019, 15). Serían expresiones graficas 
rudimentarias del sonido, una especie de sencillas onomatopeyas para entendernos. La mayoría de estos trazos que se ubican en las bocas y/o en las narices, se han interpretado como expresiones del aliento, el vaho, lenguas o vómitos de sangre (Barandiarán 1984b). Lo cierto es que encontramos trazos también en los cuerpos o las vías excretorias de algunos animales (Luís 2012, 74, fig. 4). Este autor los interpreta como "líneas cinéticas», que dependiendo de dónde se ubiquen, expresan secreciones corporales, sonidos o incluso movimientos (Luís 2012, 76). La afirmación puede parecer atrevida, pero algo parecido se ha dicho sobre los signos asociados a las aletas pectorales, ventrales y caudales del salmón de Enlène (Bégouën \& Clottes 1979, 23). Estas líneas podrían estar reflejando la estela que deja tras de sí un pez al nadar en el agua. De hecho, volvemos a encontrar un signo similar tras la cola de un pez grabado en un cuerno de ciervo de La Vache y que ha sido interpretado como la expresión del movimiento del animal en el agua (Welté 2003c, 400) ¿Es posible que se hayan representado en ocasiones, quizás de excepcionalidad creativa, los movimientos del agua o las voces de los animales? Sin llevar demasiado lejos la cuestión, ni hacer afirmaciones concluyentes al respecto, se puede considerar esta propuesta interpretativa siempre y cuando se tenga en cuenta que estamos ante fórmulas no convencionales del arte paleolítico. Lo inhabitual parece irrelevante para las aspiraciones cuantitativas del método positivista y sin embargo ofrece una información valiosa y complementaria de cómo funciona el fenómeno gráfico paleolítico (Conard 2009, 83).

A

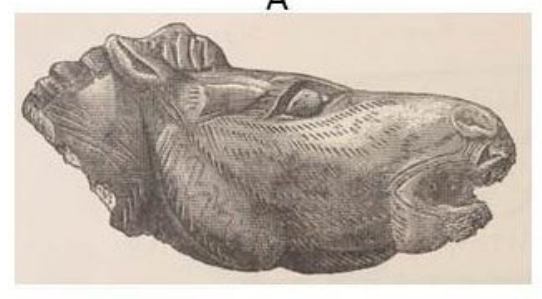

D
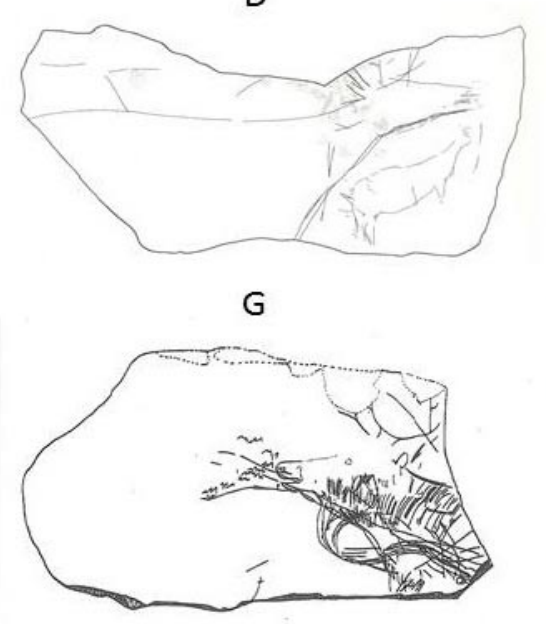

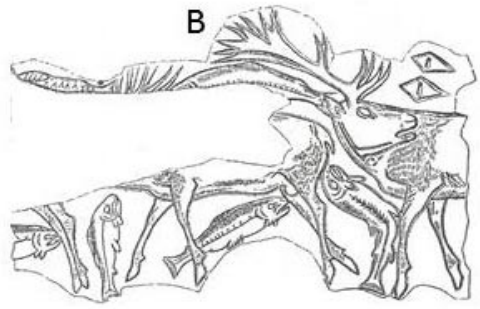

$E$
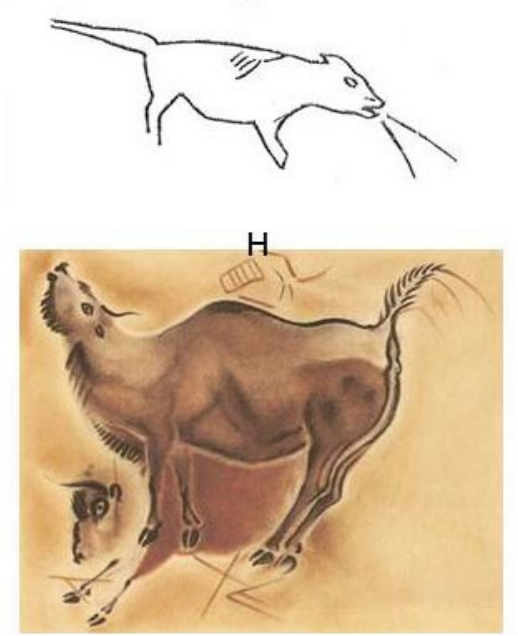
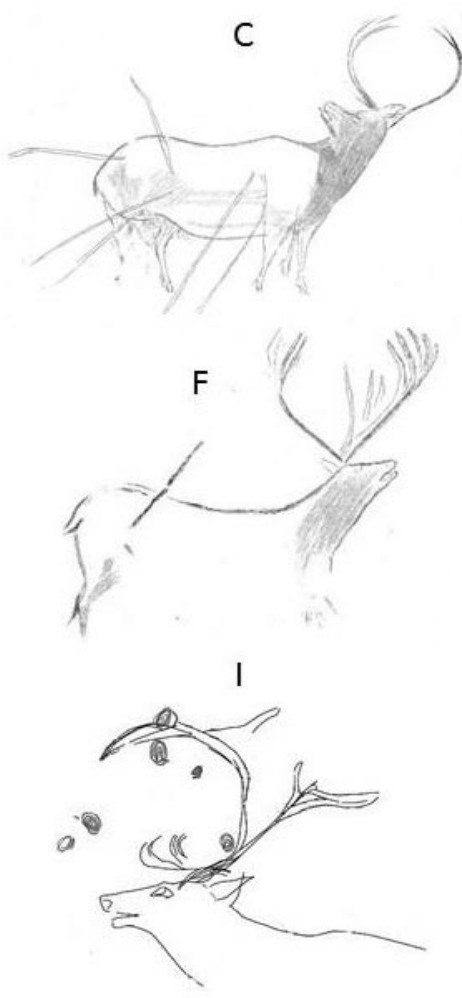

Figura 5. A (Piette 1907, 72, fig. 55). B Lortet (Piette 1907, 71, fig. 58). C Candamo (HernándezPacheco 1919, 64, fig. 14). G Parpalló (Villaverde 1994, fig. 13). E Casares (Barandirán 1984, 22, fig. 9. b). F Candamo (Hernández-Pacheco 1919, 61, fig. 12). G Fontalès (Welté 1991, 203, fig. 4). H Altamira (Obermaier \& Breuil 1984, 248, lám. XXIX). I Abauntz (Utrilla \& Mazo 2011, 36, fig. 8). 


\section{El SENTido de la puesta EN ESCEna}

Los artistas paleolíticos nos han dejado muestras de que su inventiva iba mucho más allá de las normas convencionales seguidas por una amplia tradición (Barandiarán 2017,39). En determinadas circunstancias, el aire de familia del arte paleolítico es un viento que sopla en direcciones inusuales. Una de sus raras trayectorias son los aspectos poco comunes de la puesta en escena, insólitas perspectivas y extraños efectos visuales y sonoros.

El bisonte mugiendo de Altamira fue efectuado con tanto realismo que casi se le puede oír (fig. $5 \mathrm{H}$ ). Esta y otras grafías igual de efectistas nos invitan a buscar en nuestra memoria auditiva, y a recrear en nuestra imaginación las voces de los animales. Pero nuestro adiestramiento auditivo está muy lejos de ser el de un cazador-recolector paleolítico. Además, la escritura nos ha acostumbrado a leer en silencio, es decir a separar el sonido de la palabra (McLuhan 1969, 38). Pero si se supera esta influencia histórica (Leroi-Gourhan 1971, 191), de ver las imágenes casi como si fueran letras mudas, se puede apreciar la dimensión acústica de las grafías paleolíticas en toda su extensión. No solo se percibe en la capacidad para emitir sonidos, sino también para escucharlos con atención (Luís 2019, 15), como ocurre en el caso de la cabra en alerta (Barandiarán et al. 2013). Lo que no debería dejarnos indiferentes es el hecho de que se haya seleccionado al animal en el momento en el que escucha o emite sonidos, en vez de cualquier otro. Porque en ambos casos, el sonido es un recurso al servicio de la animación, pues conecta al emisor con el oyente y viceversa, creando así un diálogo (metonímico) entre la causa y la consecuencia. La animación sonora hace que la imagen hable con..., escuche a..., implique un lenguaje visual en el que el proceso de comunicación es fundamental. El artista paleolítico, y esto es necesario recalcarlo, no está trascribiendo la realidad tal cual, porque esto es sencillamente imposible. Primero, porque la realidad no se puede abarcar nunca en su totalidad, y segundo, porque el ser humano se halla condicionado por su sistema perceptivo. A partir de ahí, podemos entender que cuando hablamos de «realidad» nos referimos a una realidad humana necesariamente mediatizada.

De todas formas, la percepción responde a la necesidad de lograr datos verídicos de esa realidad, aunque sea a partir de estímulos ambiguos e incompletos (Rock 1985, 235), trata de ajustarse a lo que se ve y lo que se percibe de una manera objetiva, usando para ello la observación y la descripción. Con razón se han considerado ambas, facetas fundamentales del arte figurado naturalista (Guy 1993, 343 y 344; Man-Estier \& Paillet 2013; Barandiarán 2017, 30). La expresión gráfica de la realidad procede de la misma forma, pues, seleccionando un instante del continuo espacio-temporal, crea un suceso ocurrido en el tiempo. Los acontecimientos que han ocurrido han sido también elegidos entre una multitud de sucesos, con la finalidad de hacerse pasar por reales. Son experiencias que hemos querido recordar para aprender determinadas cosas del mundo que nos rodea. Son extractos congelados en el tiempo de experiencias compartidas, como las fotografías de un cuaderno de bodas, tan personales como comunes. En definitiva, la elaboración gráfica naturalista no está transcribiendo la realidad tal cual, sino creando los códigos visuales necesarios para transcribirla. Si insistimos tanto en ello, es porque la transcripción grafica de lo real no es un hecho espontáneo, ni un proceso simple requiere de unas facultades cognitivas previas que aún no conocemos bien, pero sabemos se relacionan con la percepción, la memoria y la imaginación (Fritz et al. 2013, 39, Fritz et al. 2917, 347). Por ejemplo, la percepción de la profundidad, que tan difícil es de representar y que los paleolíticos sugirieron mediante la técnica del recubrimiento reservado (Barandiarán 1984a; Leroi-Gourhan 1992, 234), no solo permitió a los homínidos desenvolverse en el medio terrestre, sino que fue utilizada para extraer valiosas infor- 
maciones $^{8}$. La ventaja evolutiva no estaba en usar la percepción para reaccionar a los estímulos del entorno como cualquier otra especie, sino en usarla como un medio de conocimiento. Pruebas de esta incipiente, y en apariencia inservible curiosidad, las tenemos en los primeros homínidos (Oakley 1971). El coleccionismo de fósiles y piedras puede entenderse como una labor de observación (Lorblanchet 1999, 89-102), quizás importante si tenemos en cuenta la tecnología surgida en torno a la manipulación de la piedra (Beaune 2008). A los animales también se los observa (Hodgson \& Pettitt 2018), incluso es posible que sus huellas fueran motivo de las mismas

A llusión de profundidad en función del tamaño de las grafías asociadas

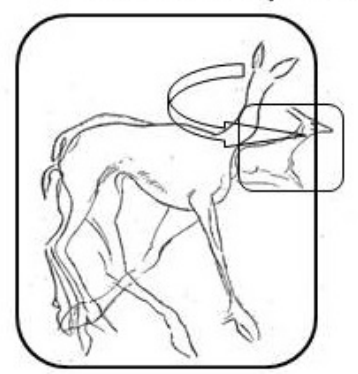

B Ilusión de profundidad en función recubrimiento reservado
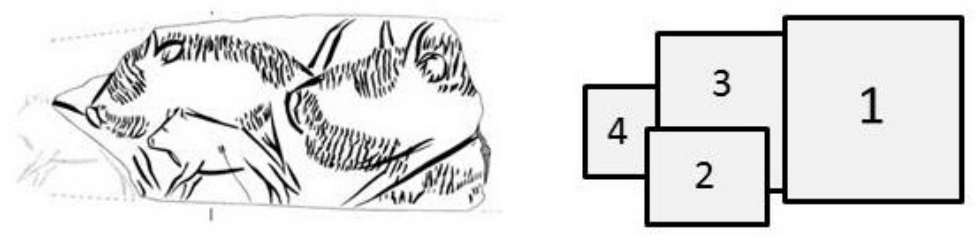

\section{Grafías frontales en movimiento, ¿desplazándose hacia atrás o hacia delante?}

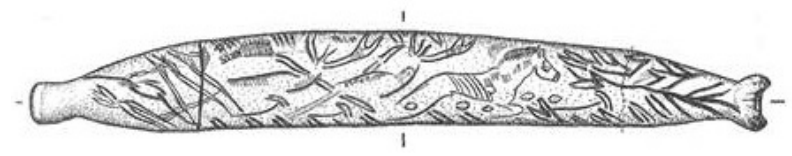

D Ángulos de visión

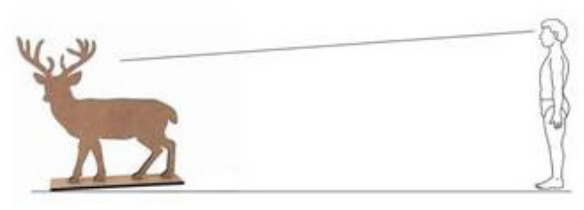

\section{¿Esquematización de serpientes?}
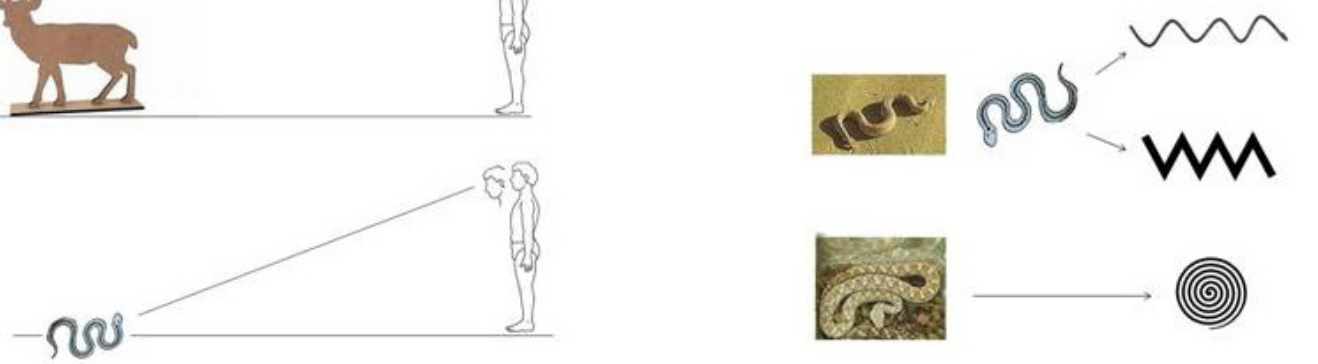

Figura 6. A Bout du Monde (Alcalde et al. 1911, fig. 222). B Morin (Deffarge et al. 1975, 35, fig. 27). C La Vache (Delporte 2003c, 393, fig. 496; Fritz y Tosello 2003, 295, fig. 350).

${ }^{8}$ Lo que los estudiosos de la visión llaman «oclusión: que un objeto más cercano a nosotros oculte parcialmente otro más alejado» (Crick 2000, 57) es uno de los medios de nuestra mente para calcular distancias y percibir la situación de los objetos en el espacio, deri- vado de nuestra visión frontal estereoscópica (Gregory 1965, 50), lo que nos capacita para tener una impresión bastante buena de la profundidad (Gregory 1965, 182), es decir, de lo que en términos narrativos sería una escena. 
elucubraciones que dieron lugar a la tecnología lítica. La superficie terrestre o la nieve han sido consideradas como un tapiz o lienzo, sobre el cual los animales han escrito «el primer libro de la naturaleza» (Février 1948, 18). Este aspecto es interesante para el caso que nos ocupa, porque las huellas establecen una clara relación entre la marca dejada en el suelo y el animal que la ha producido, lo que para el caso del arte equivale a un signo visual (Davidson 2013, 16 y 18). Como es bien sabido, las huellas de los animales aparecen en el arte prehistórico australiano (Lorblanchet $1988,299 ; 1999,222)$ y probablemente también en el arte paleolítico europeo (Delluc \& Delluc 1985, 1991, 200 fig. 143; Bahn 1986; Sanchidrián 2001, 250 y 251, fig. 101. 3). De hecho, algunos autores piensan que pudieron haber sido uno de los primeros sistemas de representación (Delluc \& Delluc 1991, 339, fig. 235), una especie de marca metonímica (visual) del animal en cuestión (White 2000,15). Ahora bien, las huellas se perciben desde arriba como una forma más o menos plana, como las serpientes y algunos reptiles, que están por debajo ángulo de visión humano. Estos animales se suelen representar bajo un punto de vista distinto, sin apenas profundidad, porque esa es su natural manera de presentarse al ojo humano. El interior de los cuerpos de las serpientes de Lortet (realizado en ligero bajo relieve) y Gourdan fueron ¿sombreados? con pequeños trazos horizontales que ofrecen cierto volumen a un animal que al moverse tan cerca del suelo, tiende a la percepción plana y esquemática. Las serpientes nos ofrecen un curioso problema de perspectiva, porque, al no tener patas y reptar por el suelo, el ser humano las suele ver desde arriba. La imagen mental que tenemos de este animal es distinta a la que nos puede proporcionar un cuadrúpedo (fig. $6 \mathrm{D}$ ). El punto de vista del Hombre como animal bípedo, desde donde ve y observa el mundo natural que le rodea, influyó sin duda en el modo de representar las serpientes y otras especies animales.

Sabemos que los paleolíticos jugaron con la simplificación de las formas naturales en los casos de cabras frontales y las figuras femeninas, pero queda la duda de si lo hicieron también con las serpientes (Breuil \& Saint-Périer 1927). Así lo creía Breuil, incluso para el caso de los bóvidos y otras especies, considerándolas como parte de un proceso llamado «degenerescencia» (Breuil 1905; 1907), pero las grafías no degeneran, más bien se generan unas a otras, conviven en un mismo imaginario, son recursos coincidentes (Barandiarán 2017, 42). El esquematismo al que son sometidas las grafías frontales es bien conocido (Barandiarán 1973, 277, fig. 45; González Sainz, 1993, 50; Paillet, 1996; Utrilla et al. 2005-06); sin embargo, no deberíamos dar por sentado que, en ausencia de los rasgos faciales, todas fueron concebidas de cara. Algunas pudieron haber sido representadas huyendo, de espaldas, en -como las concibió Breuil- una "perspectiva en huida» (Beltrán et al. 1973, 190). Tal es, o debería ser el caso de las grafías frontales que fueron concebidas en actitudes dinámicas, muy distintas de la atenta escucha, como parece ser el caso de algunos ejemplos de La Vache (Delporte 2003c, 393, fig. 496, Fritz \& Tosello 2003, 295, fig. 350), pues el movimiento natural de un animal en esa posición debería ser hacia delante o hacia atrás (fig. $6 \mathrm{C}$ ). Otra opción es que se desplacen escorzados, girando la cabeza para mirar de cara, o incluso se desplacen lateralmente, pero mirando a la grafía que tienen detrás (Piette 1907, 96) y que, por lo tanto, se situaría en un segundo plano. La observación de Piette nos obliga a revisar en qué casos es posible tener en cuenta esta posibilidad. Desde el punto de vista escenográfico, las asociaciones de Gourdan y Bout du Monde pueden interpretarse como un animal en primer plano que mira a otro situado en un segundo plano (fig. $6 \mathrm{~A}$ ). Si esto fuera cierto, estaríamos hablando de un sistema de representación en el que los intérpretes que miran hacia el interior del escenario serían una especie de observadores o testigos de la acción transcurrida en ella. Este es un recurso muy conocido en el arte histórico, pues lo encontramos en la cerámica ibérica (Olmos 2010, 142). Algo distinto es lo que ocurre con las grafías que giran la cabeza para mirar de frente, pues el movimiento de la cabeza implica una 
reacción hacia algo que está fuera del espacio gráfico. Parece lógico suponer que la mirada se dirige al observador, que de alguna forma participa, o como se diría hoy en día, interactúa con los elementos gráficos, casi como si fuera un personaje más que pudiera intervenir en la escena. Este tipo de recursos de animación, o mejor dicho de animismo gráfico (Helvenston \& Hodgson 2010), son bastante raros. Mirar al espectador, dar la espalda o ver desde lo alto un bóvido..., son posiciones anticonvencionales, que sin embargo completan los ángulos de visión de la experiencia humana y las perspectivas que les faltan a las convenciones artísticas ${ }^{9}$. Se pueden entender como un rasgo de la independencia creativa que subsiste entre los códigos estándar del arte paleolítico; grafías que se salieron de la norma para multiplicar los puntos de vista y no forman parte de la convención. Sin embargo, su existencia no es menos relevante por eso. De hecho, es esta cualidad de la perceptiva, mezclada con la imaginación, la que nos ha proporcionado una cuantiosa información para conocer no solo nuestro entorno inmediato, sino medios y modos de vida ajenos al nuestro, formas de existencia que, sin el uso de la imaginación, serían inconcebibles (Bronowski 1981). Esto es importante en lo que se refiere al arte paleolítico, porque trata de expresar (y comunicar) experiencias ajenas a las humanas, relativas a los animales. Con razón se ha dicho que la educación de la imaginación fue indispensable en la eclosión del arte figurado naturalista (Lantier 1952, 26). Se ha definido el arte como un sistema de comunicación y de preservación de la memoria (White 1994; Zilhão 2020, 142), pero lo que se memoriza y se trasmite es, sobre todo, un imaginario. Es más, la observación y la descripción, que son la base de la elaboración gráfica naturalista, son inoperantes sin el uso de la imaginación. Y es que prácticamente nada en el ser humano puede ser expresado sin imaginarse previamente. Por eso, cabe entender el lenguaje visual, y por supuesto las narraciones, como un medio de conservación del imaginario. La narrativa paleolítica, la más antigua de la que tenemos constancia, cumple sin duda alguna este papel.

\section{BiBLIOGRAFÍA}

Abramova, Z. A., 1995, L'art paléolithique d'Europe orientale et Sibérie, Grenoble: Jérôme Million.

Alcalde del río, H., H. Breuil \& L. Sierra, 1911, Les Cavernes de la Région Cantabrique (Espagne), Monaco: Imprimerie artistique Vve. A. Chène.

Aldea Hernández, A., 1991, El arte esquimal. La cultura artística esquimal y su transcendencia literaria, Madrid: Universidad Complutense de Madrid.

Altuna, J., \& J. M. Apellániz, 1976, «Las figuras rupestres paleolíticas de la cueva de Altxerri (Guipúzcoa)", Munibe XXVIII (1-3).

Anatti, E., 2017, «Decoding Paleolithic engravings on bone», Expression 16, 9-23.

Arnheim, R., 1979, Arte y percepción visual. Psicologia del arte creador, Madrid: Alianza.

Avital, T., 1998, «Footprints Literacy: The Origins of Art and prelude to Science», Symmetry: Culture and Science 9 (1), 3-46.

AzÉma, M., 1992, «La représentation du mouvement dans l'art animalier paléolithique des Pyrénées», $B u$ lletin de la Société Préhistorique Ariège Pyrénées XLVII, 19-76.

9 Quizás nos faltaría añadir un «desde abajo», pues a veces los animales, como las aves cuando vuelan, o incluso las cabras en su biotopo natural en lo alto de las montańas, se suelen ver en un ángulo de visión que es similar, desde el punto de vista de la expresión gráfica, al «desde arriba», pues ofrece una perspectiva algo plana, como ocurre por ejemplo en las aves de Raymonden (Roussot 1997, 84, fig. 44. 17), que parecen haber sido representadas en pleno vuelo. 
Azéma, M., 2010, L'art des cavernes en action. Les animaux figurés. Animation et mouvement, l'illusion de la vie, Paris: Errance.

Bahn, P., 1986, «No sex please, we're Aurignacians», Rock Art Research 3 (2), 99-120.

Balbín Behrmann, R., J. J. Alcolea González \& M. A. González Pereda, 2003, «El macizo de Ardales, un lugar mayor del arte paleolítico europeo», en: R. Balbín Behrman y P. Bueno Ramírez (eds.), El arte prehistórico desde los inicios del siglo XXI. Primer Symposium Internacional de Arte Prehistórico de Ribadasella, Asociación Cultural de Amigos de Ribadasella, 91-151.

Barandiarán, I., 1972, "Algunas convenciones de representación en las figuras animales del arte paleolítico», en: M. Almagro, M. A. García Guinea (dirs.), Santander Symposium, Santander-Madrid: U.I.S.P.P, 345-381.

Barandiarán, I., 1973, Arte mueble del paleolítico cantábrico, Zaragoza: Departamentos de Prehistoria y Arqueología e Historia de la Antigüedad de la Universidad de Zaragoza.

Barandiarán, I., 1974, «El Glotón (Gulo Gulo L.) en el Arte Paleolítico», Zephyrus XXV, 177-196.

Barandiarán, I., 1984a, "Utilización del espacio y proceso gráfico en el arte mueble paleolítico», Scripta Praehistorica Francisco Jordá Oblata, Salamanca: Ediciones Universidad de Salamanca, 113-161.

Barandiarán, I., 1984b, «Signos asociados a hocicos de animales en el arte paleolítico», Veleia 1, 7-24.

Barandiarán, I., 1993, «El lobo feroz: La vacuidad de un cuento magdaleniense», Veleia 10, 7-38.

Barandiarán, I., 2003, Grupos homoespecificos en el imaginario mobiliar magdaleniense. Retratos de familia y cuadros de género [Veleia series minor n. ${ }^{\circ}$ 21], Vitoria: Universidad del País Vasco.

Barandiarán, I., 2017, «La codificación del imaginario cotidiano: estereotipos y licencias», Veleia 34, 29-50.

Barandiarán, I., A. Cava \& E. Gundín, 2013, «La cabra alerta. Marcador gráfico del Magdaleniense cantábrico avanzado", en: M. de la Rasilla Vives (coord.), F. Javier Fortea Pérez. Universitatis Ovetensis Magister. Estudios en homenaje, Oviedo: Ménsula, 263-286.

Barbaza, M., G. Tosello, C. Fritz, G. Pinçon, J. Magail, M. Conkey, D. Gárate, S. Petrognani, O. Rivero, E. Robert \& G. Sauvet, 2017, «Iconographie et société», en: C. Fritz (dir.), L'art de la préhistoire, Paris: Citadelles \& Mazenod, 353-401.

Barrière, C., 1982, L'Art Pariétal de Rouffignac. La grotte aux cent mammouths, Paris: Picard.

Beaune, S. DE., 2008, L'homme et l'outil. L'invention technique durant la préhistoire, Paris: CNRS.

Beaune, S. DE., 2013, «De la beauté du geste technique en préhistoire», Gradhiva 17, 27-49.

Bednarik, R. G., 2016, «Rock art and Pareidolia», Rock Art Research 33 (2), 167-181.

Bégoüen, H., \& H. Breuil, 1958, Les Cavernes du Volp. Trois-Frères. Tuc d'Audoubert, Paris: Arts et Métiers Graphiques.

BÉGOuËN, C., 1929, «Sur quelques objets nouvellement découverts dans les grottes des Trois Frères (Montesquieu-Avantès, Ariège)», Bulletin de la Société préhistorique de France 26 (3), 188-196.

Bégouën, R., C. Fritz, G. Tosello, J. Clotttes, F. Faist, A. Pastoors, P. Fosse, M. langlais \& S. Lacombe, 2009, "L'art et la vie des Magdaléniens au Tuc d'Audoubert», en: R. Bégouën, C. Fritz, G. Tosello, J. Clottes, A. Pastoors, F. Faist (eds.), Le sanctuaire secret des Bisons Il y a 14000 ans la caverne du Tuc d'Audoubert, Paris: Somogy éditions d'art. Association Louis Bégouën, MonstesquieuAvantès, 59-306.

Beltrán, A., R. Gailli \& R. Robert, 1973, La cueva de Niaux, Zaragoza: Departamento de Prehistoria y Arqueología de la Universidad de Zaragoza.

Bickerton, D., 1994, Lenguaje y especies, Madrid: Alianza.

Blasco García, J. F., 1997, «Zoomorfos celtibéricos en perspectiva cenital. A propósito de los hallazgos de Cauca y El Castro «cuesta del mercado» (Coca, Segovia)», Complutum 8, 183-203.

Bosinski, G., 2011, Femmes sans tête. Une icône culturelle dans l'Europe de la fin de l'époque glaciaire, Paris: Errance.

Bowra, C. M., 1984, Poesia y canto primitivo, Barcelona: Antoni Bosch.

Braun, I. M., 2018, «Representations of Birds in the Eurasian Upper Palaeolithic Ice Age Art», Boletim do Centro Português de Geo-História e Pré-História 1 (2), 13-21. 
Breuil, H., 1905, «La dégénérescence des figures d'animaux en motifs ornementaux à l'époque du renne», Comptes rendus des séances de l'Académie des Inscriptions et Belles-Lettres 49 (1), 105-120.

Brevil, H., 1907, «Exemples de figures dégénérées et stylisées à l'époque du renne», XIII Congrès International d'Anthropologie et d'Archéologie préhistoriques, Monaco: Actes, 394-403.

Breuil, H., \& R. Jeannel, 1955, «La grotte ornée du Portel a Loubens (Ariège)», L'Anthropologie 59, $192-$ 204.

Breuil, H., \& R. De SAInt-Perier, 1927, Les poissons, les batraciens et les reptiles dans l'art quaternaire, Archives de l'Institut de Paléontologie Humaine, mémoire n. ${ }^{2}$ 2, Paris: Masson et Cie.

Breuil, H., H. Obermaier \& W. Verner, 1915, La Pileta à Benaojan (Malaga) (Espagne), Monaco: A. Chêne.

BRONOwSKI, J., 1981, Los orígenes del conocimiento y la imaginación, Barcelona: Gedisa.

Bruno, S., \& S. Maugeri, 1992, Guia de serpientes de Europa, Barcelona: Omega.

Cantalejo, P., R. Maura, M. M. Espejo, J. F. Ramos, J. Medianero, A. Aranda \& J. J. Durán, 2006, La cueva de Ardales: Arte rupestre y ocupación en el Paleolitico superior. Estudios, 1985-2005, Málaga: Diputación de Málaga. CEDMA.

Capitan, L., \& D. Peyrony, 1928, La Madeleine. Son gisement, son industrie, ses ceuvres d'art, Paris: Publications de l'Institut International d'Anthropologie.

Capitan, L., H. Breuil, P. Bourrinet \& D. Peyrony, 1906, «L'abri Mège une station magdalénienne a Teyjat (Dordogne)", Revue de l'école d'Anthropologie de Paris VI, 196-212.

Capitan, L., H. Breuil, P. Bourrinet \& D. Peyrony, 1909, "Observations sur un bâton de commandement orné de figures animales et de personnages semi-humains», Revue de l'école d'Anthropologie de Paris II, 62-76.

Carmona, R., 2005, Cómo se comenta un texto filmico, Madrid: Cátedra.

Cartailhac, E., 1874, "Congrès archéologique de France, 41 e session. Toulouse et Agen», Matériaux pour l'histoire primitive et naturelle de l'Homme, année X, série 2, tome 5, 277-289.

Cartailhac, E., \& H. Breuil, 1907, «Les œuvres d'art de la Collection de Vibraye au Muséum Natural», L'Anthropologie XVIII, 1-36.

Chevalier, J., \& A. Gheerbrant, 1986, Diccionario de los simbolos, Paris: Herder.

Chollot, M., 1964, Musée des Antiquités Nationales. Collection Piette: art mobilier préhistorique, Paris: Éditions des Musées Nationaux.

Clottes, J., 2010, La grotte Chauvet. L'art des origines, Paris: Seuil.

Conard, N. J., 2009, "Alles wird anders? Innovation und Kultureller Wandel», en: Catalogus Eiszeit. Kunst und Kultur, Stuttgart, Eiszeit: Kunst und Kultur, 82-87.

Corchón, S. R., 1986, El arte mueble paleolitico cantábrico: contexto y análisis interno, Madrid: Ministerio de Cultura.

Corballis, M. C., 2013, «Wandering tales: evolutionary origins of mental time travel and language», Frontiers in Psychology 4 (485), 1-8.

Crick, F., 2000, La búsqueda cientifica del alma, Madrid: Debate.

Cyrulnik, B., 2001, «De la conscience de soi à la spiritualité», en: P. Picq, Y. Coppens (dir.), Aux origines de l'humanité Vol. II. Le propre de l'homme, Paris: Fayard, 444-479.

Darasse, E., \& S. Guffroy, 1960, «Le Magdalénien supérieur de l'abri Fontalès, à Saint-Antonin (Tarnet-Garonne)», L'Anthropologie 64, 1-35.

Davidson, I., 2013, "Origins of Pictures: An Argument for Transformation of Signs», en: K. Sachs-Hombach, J. R. J. Schirra (eds.), Origins of Pictures: Anthropological Discourses in Image Science, Cologne: Herbert von Halem Verlag, 16-46.

Deffarge, R., P. Laurent \& D. De Sonneville-Bordes, 1975, «Art mobilier du magdalénien supérieur de l'Abri Morin a Pessac-sur-Dordogne (Gironde)», Gallia Préhistoire 18, 1-64.

Delluc, B., \& G. Delluc, 1985, «De l'empreinte au signe», Histoire et Archéologie. Les Dossiers 90, 56-62.

Delluc, B., \& G. Delluc, 1991, L'art pariétal archä̈que en Aquitaine, Paris: Centre National de la Recherche Scientifique. 
Delporte, H., 2003a, "Lissoir dit "Lissoir aux ours»", en: J. Clottes, H. Delporte (dir.), La Grotte de La Vache (Ariège) Fouilles Roman Robert. II - L'art mobilier, Paris: Réunion des musées nationaux, 293-294.

Delporte, H., 2003b, «Os d'oiseau dit la Scène d'initation», en: J. Clottes, H. Delporte (dir.), La Grotte de La Vache (Ariège) Fouilles Roman Robert. II - L'art mobilier, Paris: Réunion des musées nationaux, 360362.

Delporte, H., 2003c, Pendeloque dite Pendeloque au cheval sautant, en: J. Clottes, H. Delporte (dir.), La Grotte de La Vache (Ariège) Fouilles Roman Robert. II - L'art mobilier, Paris: Réunion des musées nationaux, 391-393.

Dissanayake, E., 2017, «From play and ritualisation to ritual and its arts: sources of Upper Pleistocene ritual practices in Lower Middle Pleistocene ritualized and play behaviors in ancestral hominids», en: C. Renfrew, I. Morley y M. Boyd (eds.), Ritual, Play and Belief in Evolution and Early Human Societies, Cambridge: Cambridge University Press, 87-99.

Drouot, E., 1953, «Les peintures de la grotte Bayol à Collias (Gard) et l'art pariétal en Languedoc méditerranéen", Bulletin de la Société préhistorique de France 50 (7-8), 392-405.

FÉvrier, J. G., 1948, Histoire de l'écriture, Paris: Payot.

FreedberG, D., 1992, El poder de las imágenes. Estudios sobre la historia y la teoría de la respuesta, Madrid: Cátedra.

Fritz, C., \& G. Tosello, 2003, «Côte», en: J. Clottes, H. Delporte (dir.), La Grotte de La Vache (Ariège) Fouilles Roman Robert. II - L'art mobilier, Paris: Réunion des musées nationaux, 295.

Fritz, C., \& G. Tosello, 2007, «La grotte de Marsoulas. Grands bisons et petits humaines», Les Dossiers d'Archéologie 324, 15-56.

Fritz, C., T. Lenssen-Erz, G. Sauvet, M. Barbaza, E. Lopez Montalvo, G. Tosello \& M. Azéma, 2013, "L'expression narrative dans les arts rupestres: approches théoriques», Les dossiers d'Archéologie $358,38-45$.

Fritz, C., G. Tosello, M. Barbaza, G. Piçon, J. Magail, M. W. Conkey, D. Gárate, S. Petrognani, O. Rivero, E. Robert, J. L. Sanchidrián \& G. Sauvet, 2017, «Art et symbolisme», en: C. Fritz (dir.), L'art de la préhistoire, Paris: Citadelles \& Mazenod, 329-350.

Gárate Maidagán, D., \& A. García Moreno, 2011, «Revisión crítica y contextualización espacio-temporal del arte parietal paleolítico de la cueva de El Niño (Ayna, Albacete)», Zephyrus LXVIII, 15-39.

Geneste, J-M., T. Hordé \& C. TAnet, 2003, Lascaux. Une ceuvre de mémoire, Périgeux: Fanlac.

Gibson, J. J., 1974, La percepción del mundo visual, Buenos Aires: Infinito.

Giraux, L., 1907, "Objets de parure solutréens provenant de Laugerie-Haute (Dordogne)», Bulletin de la Société préhistorique de France 4 (4), 213-218.

Girod, P., 1900, Les stations de l'àge du Renne dans les vallées de la Vézère et de la Corrèze. Laugerie-Basse. Industrie-Sculptures-Gravures, Paris: Librairie J-B Baillière et Fils.

Girod P., 1906, "Contribution à l'étude des bâtons percés: un nouveau bâton de La Madeleine», en: Les stations de l'âge du renne dans les vallées de la Vézère et de la Corrèze : Stations solutréennes et aurignaciennes, Paris: J.-B. Baillière et fils.

González SaInz, C., 1993, «En torno a los paralelos entre el arte mobiliar y el rupestre», Veleia 10, 39-56.

González Sainz, C., 1989, El Magdaleniense Superior-Final de la región cantábrica, Santander: TantínUniversidad de Cantabria.

Gregory, R. L., 1965, Ojo y cerebro. Psicología de la visión, Guadarrama: Madrid.

Gruber, U., 1993, Guía de las serpientes de Europa, norte de áfrica y Próximo Oriente, Barcelona: Omega.

Guy, E., 1993, "Enquête stylistique sur l'expression figurative épipaléolithique en France: de la forme au concept», Páleo 5, 333-373.

Helvenston, P., \& D. Hodgson, 2010, «The Neuropsychology of Animism: Implications for Understanding Rock Art», Rock Art Research 27 (1), 61-94.

Hernández-Pacheco, E., 1919, La Caverna de la Peña Candamo, Madrid: Museo Nacional de Ciencias Naturales. 
Hodgson, D., \& P. Pettitt, 2018, «The origins of iconic depictions: a falsifiable model derived from the visual science of Palaeolithic cave art and world rock art», Cambridge Archaeological Journal 28 (4), 591 612.

IsBeLl, L. A., 2005, «Snakes as agents of evolutionary change in primate brains», Journal of Human Evolution 51, 1-35.

Jelínek, J., 1979, Encyclopédie illustrée de L'Homme Préhistorique, Paris: Gründ.

Kanizsa, G., 1998, Gramática de la visión. Percepción y pensamiento, Barcelona: Paidós.

Kozlowski, J. K. 1992, L'Art de la Préhistoire en Europe orientale, Milano: CNRS \& Jaca Book.

LANTIER, R., 1953, "L'art rupestre naturaliste. Abbé Henri Breuil. Quatre cents siècles d'art pariétal. Les cavernes ornées de l'âge du Renne», Journal des savants, Janvier-mars, 12-19.

Leonardi, P., 1988, «Art paléolithique mobilier et pariétal en Italie», L'Anthropologie 92 (1), 139-202.

Leroi-Gourhan, A., 1971, El gesto y la palabra, Caracas: Ediciones de la Biblioteca de la Universidad de Venezuela.

Leroi-Gourhan, A., 1984, "Del soporte al abordamiento de la perspectiva en el arte paleolítico», en: Arte y grafismo en la Europa prehistórica, Madrid: Itsmo, 122-143.

Leroi-Gourhan, A., 1983, Los primeros artistas de Europa, Madrid: Encuentro.

Leroi-Gourhan, A., 1992, L'art pariétal. Langage de la préhistoire, Grenoble : Jérôme Million.

Lorblanchet, M. 1978, "De l'art préhistorique du Quercy à l'art vivant d'Australie», Bulletin de la Société des Études littéraires, scientifiques \& artistiques du Lot XCIX, 137-159.

Lorblanchet, M., 1988, "De l'art pariétal des chasseurs de rennes a l'art rupestre des chasseurs de kangourous», L'Anthropologie 92 (1), 271-316.

Lorblanchet, M., 1999, La naissance de l'art. Genèse de l'art préhistorique dans le monde, Paris: Editons Errance.

Luís, L., 2012, «Desenhos animados! Una gramática do movimento para a arte paleolítica do vale do Côa», en: M. J. Sánchez (ed.), Artes Rupestres du Pré-História e da Proto-Historia. Paradigmas e Metodologia de Registro, Lisboa: Trabalhos de Arqueologia, 69-80.

Luís, L., 2019, "25.000 anos de cinematografia no Vale do Côa. A arte paleolítica nas origens do cinema», Boletim cine clube de Viseu 161, 12-15.

Luquet, G. H., 1926, L'art et la religion des homes fossiles, Paris: Masson et Cie.

Man-Estier, E., \& P. PAillet, 2013, «Réflexions sur le réalisme et le naturalisme dans l'art préhistorique. L'exemple de l'ours", en M. Groenen (ed.), Expressions esthétiques et comportements techniques au Paléolithique, BAR Oxford, 7-36.

Mc Luhan, M., 1969, La galaxia Gutenberg. Génesis del homo typographicus, Madrid: Aguilar.

Massi, A., M. Coltorti, F. D’Errico, M. Mussi \& D. Zampetti, 1997, «La «Venere» de Tolentino e i pioneri della ricerca archeologica», Origini: Preistoria e protostoria delle civiltà antiche 21, 23-66.

Mithen, S., 1998, Arqueología de la mente. Origenes del arte, de la religión y de la ciencia, Barcelona: Crítica.

OAKley, K. P., 1971, "Fossils collected by the earlier palaeolithic men», en: Mélanges de préhistoire, d'archéocivilisation et d'ethnologie offert à André Varagnac, Paris: sevpen, 581-584.

Obermaier, H., \& H. Breuil, 1984, La cueva de Altamira en Santillana del Mar, Madrid: Viso.

Olmos, R., 2010, «Viajes iniciáticos en Grecia y en Iberia: un recorrido iconográfico hacia el reino de lo desconocido", en: F. Marco Simón, F. Pina Polo, J. Remesal Rodríguez (eds.), Viajeros, peregrinos y aventureros en el mundo antiguo, Barcelona: Publications i Editions Universitat de Barcelona, 115-146.

OMnes, J., 1984, «Le sanctuaire magdalénien de la grotte de Labastide (Hautes-Pyrénées, France)», Munibe $36,19-26$.

Paillet, P., 1996, «A propos de trois bisons magdaléniens exceptionnels (La Madeleine, Dordogne)», Paléo 8, 359-366.

Pastoors, A., T. Lessen-Erz, T. Ciqae, U. Kxunta, T. Thao, R. Bégouën, M. Biesele \& J. Clottes, 2015, «Tracking in Caves: Experience based Reading of Pleistocene human footprints in French caves», Cambridge Archaeological Journal 25 (3), 551-564.

Patte, E., 1960, Les Hommes Préhistoriques et la Religion, Paris: A. et J. Picaud et Cie. 
Pérez Ripoll, M., \& J. A. Raga, 1998, «Los mamíferos marinos en la vida y en el arte de la Prehistoria de la Cueva de Nerja», en: J. L. Sanchidrián, M. D. Simón (eds.), Las culturas del Pleistoceno Superior en Andalucía, Málaga, 251-275.

Piette, E., 1874, «La grotte de Lortet pendant l'âge du renne», Bulletins de la Société d'anthropologie de Paris $\mathrm{II}^{\circ}$ série, 9, 298-317.

Piette, E., 1904, «Études d'ethnographie préhistorique. VII. Classification des sédiments formés dans les cavernes pendant l'âge du renne», L'Anthropologie 15, 129-176.

Piette, E., 1907, L'Art pendant l'Age du Renne. Album de cent planches dessinées par J. Pilloy, Paris: Masson et Cie.

Pigeaud, R., S. Hinguant, H. Paitier, V. Pommier \& P. Bonic, 2012, «La grotte Margot (Thorigné-enCharnie, Mayenne): un sanctuaire complexe aux influences multiples», Bulletin de la Société Préhistorique Ariège-Pyrénées LXVII, 81-101.

RÉdou, A., 2006, «L'Homme et l'Eau au travers de l'Art du Paléolithique supérieur en France et en Espagne», Bulletin Préhistoire du Sud-Ouest 13, 89-98.

ReInACH, S., 1913, Répertoire de l'Art Quaternaire, Paris: Ernest Leroux.

Rock, I., 1985, La percepción, Barcelona: Labor.

Romero Carnicero, F., 2010, "Las representaciones zoomorfas en perspectiva cenital. Un estado de la cuestión», en: F. Romero Carnicero, C. Sanz Mínguez (eds.), De la Región Vaccea a la Arqueología Vaccea, Valladolid: Centro de Estudios Vacceos «Federico Wattenberg» de la Universidad de Valladolid, 467-545.

Roussot, A., 1997, L'art préhistorique, Luçon: Éditions Sud Ouest.

SAINT-PÉRIER, R. DE., 1924, "Les fouilles de 1923 dans la grotte des rideaux a Lespugue (Haute-Garonne)», L'Anthropologie XXXIV (1-2), 1-15.

SANChidrí́N, J. L., 2001, Manual de arte prehistórico, Barcelona: Ariel.

San Juan-Foucher, C., 2014, "Côte», en: L. Mons, S. Péan y R. Pigeaud (dir.), Matières d'art. Représentations préhistoriques et supports osseux relations et contraires, Paris: Errance, 107-140.

Schacter, D., \& D. R. Addis, 2009, «Remembering the Past To Imagine the Future: A Cognitive Neuroscience Perspective», Military Psychology 21, 108-112.

Silberbauer, G., 1983, Cazadores del desierto. Cazadores y hábitats en el desierto de Kalahari, Barcelona: Mitre.

Taçon, P. S. C., L. Gang, Y. Decong, S. K. May, L. Hong, M. Aubert, J. Xueping, D. Curnoe \& A. I. R. Herries, 2010, "Naturalism, Nature and Questions of Style in Jinsha River Rock Art, Northwest Yunnan, China», Cambridge Archaeological Journal 20 (1), 67-86.

Tomasello, M., 2013, Los orígenes de la comunicación humana, Buenos Aires: Katz.

Tosello, G., 2003, Pierres gravées du Périgord magdalénien. Art, symboles, territoires, Paris: CNRS.

Tosello, G., \& C. Fritz, 2013, «Pierres à histoires», Les Dossiers d’Archéologie 358, 52-57.

Trilles, R. P., 1931, Les Pymées de la Forêt Equatoriale, Paris: Librairie Bloud \& Gay.

Utrilla, P., \& M. Martínez Bea, 2005-06, "La captura del ciervo vivo en el arte prehistórico», $M u$ nibe 57, 161-178.

Utrilla, P., \& C. Mazo, 2011, «Los cantos pintados de la cueva de Abauntz y algunas nuevas lecturas del bloque 1", Príncipe de Viana 253, 23-41.

Utrilla, P., C. Mazo, M. C. Sopena, R. Domingo \& M. Martínez-Bea, 2007-08, «Ríos, montañas y charcas: una representación del paisaje en el bloque 1 de la cueva de Abauntz», Veleia 24-25, 229-260.

VictorRi, B., 2002, «Homo narrans: le rôle de la narration dans l'émergence du langage», Langages 36e année, $146,112-125$.

Villaverde, V., 1994, Arte paleolitico de la Cova del Parpalló. Estudio de la colección de plaquetas y cantos grabados y pintados, Valencia: Servei d'Investigació Prehistórica.

White, R., 1994, «Les archives du Paléolithique», La Recherche 267 (35), 746-750.

White, R., 2000, «Un Big Bang socioculturel», La Recherche 4, 10-16. 
Welté, A.-C., 1991, «Analyse du décor d'un os d'oiseau de l'abri Montastruc (Tarn-et-Garonne) conservé au British Museum", Bulletin de la Société Préhistorique d'Ariège-Pyrénées 46, 199-210.

Welté, A-C., 2003a, «Armature de sagaie à biseau double», en: J. Clottes, H. Delporte (dir.), La Grotte de La Vache (Ariège) Fouilles Roman Robert. II - L'art mobilier, Paris: Réunion des musées nationaux, 125125.

Welté, A-C., 2003b, "Côte», en: J. Clottes, H. Delporte (dir.), La Grotte de La Vache (Ariège) Fouilles Roman Robert. II - L'art mobilier, Paris: Réunion des musées nationaux, 318.

Welté, A-C., 2003c, «Bois de cervidé dit Le Poignard», en: J. Clottes, H. Delporte (dir.), La Grotte de La Vache (Ariège) Fouilles Roman Robert. II - L'art mobilier, Paris: Réunion des musées nationaux, 400401.

Zilhão, J., 2020, «Los orígenes del arte», en: I. Domingo, P. Antoni (eds.), Art primer. Artistes de la prehistòria, Barcelona: Museu d'Arqueologia de Catalunya, 34-199. 